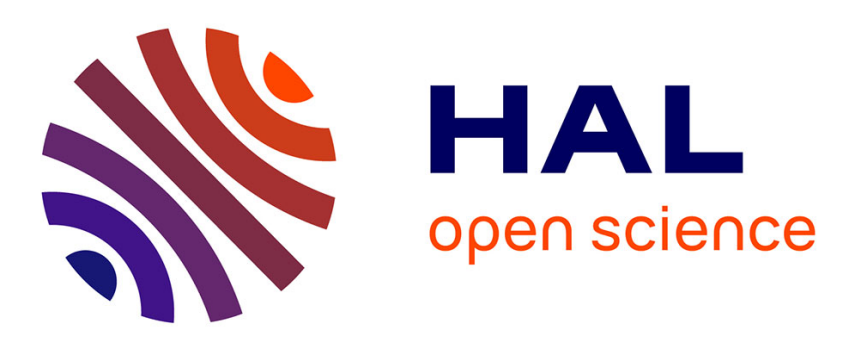

\title{
Effect of interfacial heat transfer on the onset of oscillatory convection in liquid bridge
}

Bo Xun, Kai Li, Paul G. Chen, Wen-Rui Hu

\section{To cite this version:}

Bo Xun, Kai Li, Paul G. Chen, Wen-Rui Hu. Effect of interfacial heat transfer on the onset of oscillatory convection in liquid bridge. International Journal of Heat and Mass Transfer, 2009, 52 (19-20), pp.4211-4220. 10.1016/j.ijheatmasstransfer.2009.04.008 . hal-01307193

\section{HAL Id: hal-01307193 \\ https://hal.science/hal-01307193}

Submitted on 28 Apr 2016

HAL is a multi-disciplinary open access archive for the deposit and dissemination of scientific research documents, whether they are published or not. The documents may come from teaching and research institutions in France or abroad, or from public or private research centers.
L'archive ouverte pluridisciplinaire HAL, est destinée au dépôt et à la diffusion de documents scientifiques de niveau recherche, publiés ou non, émanant des établissements d'enseignement et de recherche français ou étrangers, des laboratoires publics ou privés. 


\title{
Effect of interfacial heat transfer on the onset of oscillatory convection in liquid bridge
}

\author{
Bo Xun ${ }^{1,3}$, Kai Li $i^{1}$, Paul Gang Chen ${ }^{2}$ and Wen-Rui Hu ${ }^{l}$
}

1 National Microgravity Laboratory, Institute of Mechanics, Chinese Academy of Sciences, Beijing 100080, China

${ }^{2}$ Laboratoire Modélisation et Simulation Numérique en Mécanique et Génie des Procédés, UMR 6181, CNRS-Universités d'Aix-Marseille, F-13451 Marseille Cedex 20, France

3 The Graduate School of Chinese Academy of Sciences, Beijing 100080, China

Corresponding author

Kai Li

National Microgravity Laboratory, Institute of Mechanics, Chinese Academy of Sciences, Beijing 100080, China

Tel: $+86-10-82544100$

Fax: +86-10-82544096

e-mail: likai@imech.ac.cn 


\begin{tabular}{|c|c|c|c|}
\hline \multicolumn{4}{|c|}{ Nomenclature } \\
\hline A & $\begin{array}{l}\text { matrix in eigenvalue } \\
\text { problem }\end{array}$ & $\operatorname{Re}_{c}$ & critical Reynolds nmber \\
\hline B & $\begin{array}{l}\text { matrix in eigenvalue } \\
\text { problem }\end{array}$ & $s$ & Surface of the liquid bridge \\
\hline$B$ & Buoyant effect & $S$ & $\begin{array}{l}\text { Dimensionless } \\
\text { tensor, } \frac{1}{2}\left(\nabla \vec{U}+(\nabla \vec{U})^{T}\right)\end{array}$ \\
\hline$B i$ & Biot number, $\frac{h R}{k}$ & $T$ & dimensionless time \\
\hline Bo & $\begin{array}{l}\text { static } \\
\text { number, } \frac{\rho_{0} g R^{2}}{\sigma_{0}}\end{array}$ & $\vec{t}_{z}$ & $\begin{array}{l}\text { the unit vector tangent to the free surface in } \\
\text { the }(r, z) \text { plane }\end{array}$ \\
\hline $\mathrm{Ca}$ & Capillary number, $\frac{\gamma \Delta T}{\sigma_{0}}$ & $\vec{t}_{\varphi}$ & $\begin{array}{l}\text { the unit vector tangent to the free surface in } \\
\text { the }(\mathrm{r}, \varphi) \text { plane }\end{array}$ \\
\hline$D_{k}$ & mechanical dissipation & $T$ & dimensionless temperature \\
\hline$D_{t h}$ & thermal dissipation & $T_{0}$ & $\begin{array}{l}\text { mean temperature of the upper and lower } \\
\text { ends }\end{array}$ \\
\hline$E_{k}$ & $\begin{array}{l}\text { Kinetic energy of } \\
\text { disturbances }\end{array}$ & $T_{a m b}$ & $\begin{array}{l}\text { dimensionless temperature of the ambient } \\
\text { air }\end{array}$ \\
\hline$E_{t h}$ & $\begin{array}{l}\text { "thermal" energy of } \\
\text { disturbances }\end{array}$ & $T_{\text {cold }}$ & dimensionless temperature on the cold rod \\
\hline g & $\begin{array}{l}\text { gravitational } \\
\text { acceleration }\end{array}$ & $\vec{U}$ & dimensionless velocity vector,$(u, v, \quad w)$ \\
\hline
\end{tabular}




\begin{tabular}{|c|c|c|c|}
\hline $\mathrm{g}_{0}$ & $\begin{array}{l}\text { normal gravitational } \\
\text { acceleration, } \\
9.806\left(\mathrm{~kg} \cdot \mathrm{m} / \mathrm{s}^{2}\right)\end{array}$ & $|w|_{\max }$ & maximal value of $|w|$ on the free surface \\
\hline$G r$ & $\begin{array}{l}\text { Grashof } \\
\text { number, } \frac{g \beta \Delta T R^{3}}{v^{2}}\end{array}$ & $X$ & $\begin{array}{l}\text { vector composed of disturbance velocity, } \\
\text { pressure and temperature, } \\
\left(u^{\prime}, i v^{\prime}, w^{\prime}, p^{\prime}, T^{\prime}\right)^{\mathrm{T}}\end{array}$ \\
\hline $\mathrm{h}$ & $\begin{array}{l}\text { heat transfer coefficient } \\
\text { on free surface }\end{array}$ & $X$ & $\begin{array}{l}\text { the basic steady axisymmetric state, } \\
\left\{\vec{U}(r, z)=U \vec{e}_{r}+W \vec{e}_{z}, P(r, z), T(r, z)\right\}\end{array}$ \\
\hline$h(z)$ & free surface local radius & $(r, \quad \theta, z)$ & cylindrical coordinates \\
\hline$i$ & $\sqrt{-1}$ & $V_{0}$ & the liquid volume with cylindrical shape \\
\hline$I$ & $\begin{array}{l}\text { Interactive term in } \\
\text { kinetic energy equation }\end{array}$ & $\begin{array}{l}\text { Greek } \\
\text { symbols }\end{array}$ & \\
\hline $\begin{array}{l}J_{1} \\
J_{2}\end{array}$ & $\begin{array}{l}\text { Interactive term in } \\
\text { "thermal" energy } \\
\text { equation decomposed in } \\
\text { cylindrical coordinates }\end{array}$ & $\alpha$ & thermal diffusivity coefficient \\
\hline $\mathrm{k}$ & $\begin{array}{l}\text { thermal conductivity } \\
\text { coefficient }\end{array}$ & $\beta$ & thermal expansion coefficient \\
\hline $\mathrm{L}$ & $\begin{array}{l}\text { height of the liquid } \\
\text { bridge }\end{array}$ & $\Delta T$ & $\begin{array}{l}\text { applied temperature difference between } \\
\text { two solid ends }\end{array}$ \\
\hline $\begin{array}{l}M_{1}, M_{2} \\
M_{3}\end{array}$ & $\begin{array}{l}\text { Work done by } \\
\text { thermocapillary force }\end{array}$ & $\gamma$ & $\begin{array}{l}\text { negative temperature gradient of surface } \\
\text { tension }\end{array}$ \\
\hline
\end{tabular}




\begin{tabular}{|c|c|c|c|}
\hline & $\begin{array}{l}\text { decomposed in } \\
\text { cylindrical coordinates }\end{array}$ & & \\
\hline$\vec{n}$ & $\begin{array}{l}\text { the outward-directed } \\
\text { normal vector of the } \\
\text { free surface }\end{array}$ & $\Gamma$ & aspect ratio, $\frac{L}{R}$ \\
\hline$N_{z}$ & $\begin{array}{l}\text { number of the grid } \\
\text { points in axial direction }\end{array}$ & $\mu$ & dynamic viscosity coefficient \\
\hline$N_{r}$ & $\begin{array}{l}\text { number of the grid } \\
\text { points in radial direction }\end{array}$ & $v$ & kinematic viscosity coefficient \\
\hline$P$ & dimensionless pressure & $(\xi, \eta)$ & coordinates in computational domain \\
\hline$P_{s}$ & $\begin{array}{l}\text { dimensionless static } \\
\text { pressure }\end{array}$ & $|\psi|_{\max }$ & $\begin{array}{l}\text { maximal absolute value of the stream } \\
\text { function }\end{array}$ \\
\hline $\operatorname{Pr}$ & Prandtl number, $\frac{v}{\alpha}$ & $\rho_{0}$ & mean density \\
\hline$Q$ & $\begin{array}{l}\text { "thermal" energy } \\
\text { transport from the free } \\
\text { surface }\end{array}$ & $\sigma_{0}$ & mean free surface tension \\
\hline $\mathrm{R}$ & $\begin{array}{l}\text { radius of the liquid } \\
\text { bridge }\end{array}$ & $\sigma(m)$ & $\begin{array}{l}\text { the complex growth rate of the } \\
\text { corresponding perturbation mode }\end{array}$ \\
\hline $\operatorname{Re}$ & $\begin{array}{l}\text { Reynolds number, } \\
\frac{\gamma \Delta T R}{\mu v}\end{array}$ & $\Omega$ & $\begin{array}{l}\text { Volume domain occupied by the liquid } \\
\text { bridge }\end{array}$ \\
\hline
\end{tabular}




\begin{abstract}
In present study, effect of interfacial heat transfer with ambient gas on the onset of oscillatory convection in a liquid bridge of large Prandtl number on the ground is systematically investigated by the method of linear stability analyses. With both the constant and linear ambient air temperature distributions, the numerical results show that the interfacial heat transfer modifies the free surface temperature distribution directly and then induces a steeper temperature gradient on the middle part of the free surface, which may destabilize the convection. On the other hand, the interfacial heat transfer restrains the temperature disturbances on the free surface, which may stabilize the convection. The two coupling effects result in a complex dependence of the stability property on the Biot number. Effects of melt free-surface deformation on the critical conditions of the oscillatory convection were also investigated. Moreover, to better understand the mechanism of the instabilities, rates of kinetic energy change and "thermal" energy change of the critical disturbances were investigated
\end{abstract}

Keywords: liquid bridge, interfacial heat transfer, oscillatory convection, critical condition 


\section{Introduction}

Floating-zone (FZ) technique is a crucible-free process for the growth of high quality single crystal, which the melt zone is confined by the surface tension of melt free surface. However, the diameter of the grown crystal is limited under the terrestrial condition due to easy breakage of the melt zone induced by gravity. The essential reason to go to space for melt growth of single crystals lies in a promise that a substantial reduction of gravity level achieved in spacecraft may result in a quiescent melt pool, thereby allowing a diffusion-controlled growth condition to be realized. Moreover, the microgravity environment provides the possibility of growing large size crystal by the FZ technique. However, experimental facts revealed that during the FZ process in microgravity, thermocapillary flow driven by the surface tension gradient of the melt free surface, depending on such factors like temperature, solutal concentration, electric potential etc., occurs in the melt zone even when the buoyancy-driven flow is greatly reduced. The thermocapillary flow may be oscillatory when the Reynolds number exceeds certain critical value and responsible for striations in crystals grown in space [1]. Therefore, numerous experimentations and analytical studies (linear instability analyses and direct numerical simulations) have been devoted to the oscillatory thermocapillary flows in liquid bridge model (see Fig.1) mimicking the half of FZ for the sake of simplicity during the last decades. It is now well established that a steady axisymmetric (2D) thermocapillary flow loses its stability first to a steady asymmetric (3D) flow and then to an oscillatory flow in 
liquid bridges of low Prandtl numbers $(\operatorname{Pr} \leq 0.06)$ while it loses its stability directly to an oscillatory flow (3D) in those of large Pr numbers [2]. On the other hand, the corresponding critical conditions determined through the analytical studies can not agree well with the experimental results in quantity, especially for high $\operatorname{Pr}$ number fluids. It is noted that most of the analytical studies on the liquid bridge were carried out with an adiabatic melt free surface assumption, i.e., there is no heat transfer across the melt free surface. In practice, interfacial heat transfer in the experimentations, especially under high temperature conditions, may play an important role in the flow dynamics (for example, see [3-8]). Kamotani et al. [3] studied the effect of interfacial heat loss in liquid bridges of high Pr fluids considering the ambient air flow. They calculated the average interfacial heat transfer rate (indicated non-dimensionally as average Biot number in their notation), and found that the critical conditions decrease with the increased heat loss when the average Biot number is less than 1.5. Melnikov and Shevtsova [7] numerically investigated the effect of interfacial heat transfer on the thermocapillary flow in a liquid bridge of $\operatorname{Pr}=14$ with aspect ratio equal 1.8 under normal gravity condition, and the ambient air temperature was assumed to equal the cold rod temperature. They found that the heat loss leads to destabilization of the flow at small Biot numbers $(B i \leq 2)$ contrary to the stabilization of the flow at large $B i$ numbers $(B i \geq 5)$. Similarly, Kousaka and Kawamura [5] studied the thermocapillary flow in a liquid bridge of $\operatorname{Pr}=28.1$ with unitary aspect ratio under zero gravity condition, and a linear ambient air temperature distribution was adopted. In their case, 
in the range of small $B i$ numbers $(B i<1)$, there is heat loss through the free surface near the cold rod and heat gain near the hot rod, and the destabilization of the thermocapillary flow by the interfacial heat transfer was also found. Recently, Wang et al. [8] studied the situation with interfacial heat gain. They found that the critical conditions are not significantly affected by the interfacial heat gain, and there is a big jump of the critical conditions when the interfacial heat transfer is changed from heat gain to heat loss [3]. However, the aforementioned results are fragmental due to the computation task of 3D direct numerical simulation, and the detailed dependency of the critical conditions on the interfacial heat transfer is still lacking. On the other hand, to the end of the manipulation of oscillatory thermocapillary flow through varying the interfacial heat exchange, extensive preliminary experimental studies should be conducted on the ground due to the scarce space experiment opportunity. Therefore, the effect of melt free-surface deformation, which is usually ignored in previous studies such as [7], should be taken into account.

In present study, linear stability analyses were conducted to systematically investigate the dependency of the critical conditions of oscillatory convection on the interfacial heat transfer under normal gravity condition with both the constant and linear ambient air temperature distributions (The studies on the corresponding cases in the microgravity environment will be reported elsewhere). Moreover, effects of melt free-surface deformation on the critical conditions of oscillatory convection were investigated. 


\section{Governing Equations and Numerical schemes}

Figure 1 shows the scheme diagram of the liquid bridge considered in the present study. The liquid bridge is formed by 1 cst oil with height $\mathrm{L}$, radius $\mathrm{R}$ and an applied temperature difference $\Delta T$ between two solid ends. The local radius of the melt free surface is denoted as $\mathrm{h}(\mathrm{z})$. The length, velocity, pressure and time are scaled by $\mathrm{R}$, $\frac{\gamma \Delta T}{\mu}, \frac{\gamma \Delta T}{R}$ and $\frac{R^{2}}{v}$ respectively, and the temperature measured with respect to $T_{0}$ is scaled by $\Delta T$, where $T_{0}$ is the mean temperature of the upper and lower ends, $\mu$ the dynamic viscosity coefficient, $v$ the kinematic viscosity coefficient and $\gamma$ the negative temperature gradient of surface tension. The Reynolds number, Prandtl number, Grashof number, aspect ratio, Biot number and static Bond number are defined as follows respectively,

$\operatorname{Re}=\frac{\gamma \Delta T R}{\mu v}, \operatorname{Pr}=\frac{v}{\alpha}, G r=\frac{g \beta \Delta T R^{3}}{v^{2}}, \Gamma=\frac{L}{R}, B i=\frac{h R}{k}$, Bo $=\frac{\rho_{0} g R^{2}}{\sigma_{0}}$

where $\alpha$ is the thermal diffusivity coefficient, h the heat transfer coefficient, $\rho_{0}$ the mean density, $\sigma_{0}$ the melt surface tension and $g$ the acceleration of gravity. The thermophyscical properties of 1 cst silicone oil are listed in Table $\mathbf{1}$.

In the cylindrical coordinate $(r, \theta, z)$, the non-dimensional governing equations are as follows:

$$
\nabla \cdot \vec{U}=0
$$

$\frac{\partial \vec{U}}{\partial t}+\operatorname{Re}(\vec{U} \bullet \nabla) \vec{U}+\nabla P=\Delta \vec{U}+\frac{G r}{\operatorname{Re}} T \overrightarrow{e_{z}}$

$\frac{\partial T}{\partial t}+\operatorname{Re}(\vec{U} \bullet \nabla) T=\frac{1}{\operatorname{Pr}} \Delta T$

where $\vec{U}=(u, v, w)$ indicates the dimensionless velocity vector, $P$ the pressure, $T$ 
the temperature and $t$ the time. The corresponding boundary conditions are as following:

$$
\begin{aligned}
& z=0, \Gamma: \vec{U}=0, T=\mp \frac{1}{2} \\
& r=\mathrm{h}(\mathrm{z}): \vec{n} \bullet \vec{U}=0, \vec{t}_{z} \bullet(S \bullet \vec{n})=-\vec{t}_{z} \bullet \nabla T \\
& \vec{t}_{\varphi} \bullet(S \bullet \vec{n})=-\vec{t}_{\varphi} \bullet \nabla T, \vec{n} \bullet \nabla T=-B i\left(T-T_{a m b}\right)
\end{aligned}
$$

where $T_{a m b}$ indicates the dimensionless ambient air temperature, $S=\frac{1}{2}\left(\nabla \vec{U}+(\nabla \vec{U})^{T}\right)$ the stress tensor in non-dimensional form. The Vector $\vec{n}$ is the outward-directed normal vector of the free surface, and the vectors $\vec{t}_{z}$ and $\vec{t}_{\varphi}$ denote the unit vector tangent to the melt free surface in the $(r, z)$ plane and $(r, \varphi)$ plane respectively.

Considering the asymptotic limit of capillary number, $C a=\frac{\gamma \Delta T}{\sigma_{0}} \rightarrow 0$, the melt free surface shape is symmetric to the axis of melt zone and the normal-stress balance can be approximated by the Young-Laplace equation:

$P_{s}=\nabla \cdot \vec{n}+\operatorname{Bo} z$

where $P_{s}$ is the dimensionless static pressure. Before calculating the flow and temperature fields, the free surface shape $h(z)$ is determined by Eq. (7) with the liquid bridge volume equal $\pi R^{2} L$. As shown in Fig. 1 , if $\mathrm{Bo}=0$, the free surface shape is cylindrical with $\mathrm{h}(\mathrm{z})=1$ as indicated by the dashed lines (hereafter, we use $\mathrm{h}(\mathrm{z})$ to indicate the dimensionless local radius of the free surface without confusion) while Bo $\neq 0$, the free surface is curved as indicated by the solid lines. For the case with curved free surface shape, the body-fitted curvilinear coordinates are employed. The original physical domain in the $(\mathrm{r}, \mathrm{z})$ plane occupied by the liquid bridge is 
transformed into a rectangular computational domain in the $(\xi, \eta)$ plane by the transformation:

$$
\left\{\begin{array}{l}
\xi=\frac{r}{h(z)} \\
\eta=z
\end{array}\right.
$$

For the sake of brevity, the details of the transformed equations in the curvilinear coordinates $(\xi, \eta)$, which is the same as the excellent work [9], are not shown here. For the linear stability analysis, the basic steady axisymmetric state, $X=\left\{\vec{U}(r, z)=U \vec{e}_{r}+W \vec{e}_{z}, P(r, z), T(r, z)\right\}$, is first determined for a given set of parameters (Re, Pr, $B i$ and $\Gamma$ ), and then small three-dimensional disturbances are added to the basic state and linearized by neglecting high orders of disturbances [10-12]. The disturbances are assumed to be in the normal mode:

$$
\left(\begin{array}{c}
\vec{u}^{\prime} \\
p^{\prime} \\
T^{\prime}
\end{array}\right)=\sum_{m=-\infty}^{+\infty}\left(\begin{array}{l}
\vec{u}^{\prime m}(r, z) \\
p^{\prime m}(r, z) \\
T^{\prime m}(r, z)
\end{array}\right) \exp [\sigma(m) t+j m \phi],
$$

where the variables with prime denote the disturbances, $m$ the azimuthal wave number, $\sigma(m)$ the complex growth rate of the corresponding perturbation mode, and $i=\sqrt{-1}$. The discrete form of the linearized equations can be written as a generalized eigenvalue problem:

$$
\mathrm{g}(x, X, \operatorname{Re}, m, \operatorname{Pr}, \Gamma, B i) \equiv \mathrm{A} x=\mathrm{B} x,
$$

where $x=\left(u^{\prime}, i v^{\prime}, w^{\prime}, p^{\prime}, T^{\prime}\right)^{\mathrm{T}}$ denotes a vector composed of disturbance velocity, pressure and temperature. $\mathrm{A}$ is a real-valued non-symmetric matrix, while $\mathrm{B}$ is a singular real-valued diagonal matrix. The eigenvalues and related eigenfunctions of problem (8) are solved by the Arnoldi method [13]. The critical Reynolds number 
$\operatorname{Re}_{c}$ is obtained when the maximal real part of $\sigma(m)$ for all $\mathrm{m}$ is zero.

In order to well resolve the boundary layers at both ends, a non-uniform grid with denser points near both solid ends and free surface is adopted in this study. The grid we used in the calculation is $N_{r} \times N_{z}=81 \times 141$, where $N_{r}$ and $N_{z}$ indicate the number of the grid points in radial and axial direction respectively. Moreover, to validate the present code under curved free surface situation, we reproduced some calculations in the work [9] and [14] using their definitions of the dimensionless numbers, and the computed results show good agreement (see Table 2).

Moreover, to better understand the mechanism of the instabilities, rates of kinetic energy $\left(E_{k}\right)$ change and "thermal" energy $\left(E_{t h}\right)$ change of the critical disturbances were investigated in the following way: the disturbance equations for momentum and temperature [10-12] were multiplied by the velocity and temperature disturbances respectively, and then integrated over the volume of liquid bridge and normalized by the mechanical dissipation $\left(D_{k}\right)$ and thermal dissipation $\left(D_{t h}\right)$ respectively, thus the following equations were obtained:

$$
\begin{gathered}
\frac{1}{D_{k}} \frac{d E_{k}}{d t}=M_{1}+M_{2}+M_{3}+B+I-1, \\
\frac{1}{D_{t h}} \frac{d E_{t h}}{d t}=Q+J_{1}+J_{2}-1 .
\end{gathered}
$$

where $E_{k}=\int_{\Omega} \frac{\vec{u}^{\prime 2}}{2} d \Omega, \quad E_{t h}=\int_{\Omega} \frac{T^{\prime 2}}{2} d \Omega, \quad D_{k}=\int_{\Omega} \frac{S^{\prime}: S^{\prime}}{2} d \Omega, \quad D_{t h}=\int_{\Omega} \frac{\nabla T^{\prime} \bullet \nabla T^{\prime}}{\operatorname{Pr}} d \Omega$ are the integrations over the volume of liquid bridge ( $\Omega$ ) respectively, $M=-\frac{1}{D_{k}} \int_{s} \vec{u}^{\prime} \bullet \nabla T^{\prime} d s=M_{1}+M_{2}+M_{3}=-\frac{1}{D_{k}} \oiiint_{s} u^{\prime} \frac{\partial T^{\prime}}{\partial r} d s-\frac{1}{D_{k}} \int_{s} v^{\prime} \frac{\partial T^{\prime}}{\partial \varphi} d s-\frac{1}{D_{k}} \oint_{s} w^{\prime} \frac{\partial T^{\prime}}{\partial z} d s$ 
the integrations over the surface of $\Omega$ denoting the work done by the thermocapillary force induced by the temperature disturbance per unit time, $B=\frac{G r}{\operatorname{Re}} \int_{\Omega} w^{\prime} T^{\prime} d \Omega$ the work done by the buoyant force, $I=-\frac{\operatorname{Re}}{2} \int_{\Omega} \vec{u}^{\prime} \bullet S \bullet \vec{u}^{\prime} d \Omega$ the interactive term between the basic state stress tensor and the velocity disturbance, $Q=-\frac{B i}{\operatorname{Pr}} \oint_{s} T^{\prime 2} d s$ the transport of "thermal" energy through the free surface, and $J=-\frac{\operatorname{Re}}{D_{t h}} \int_{\Omega}\left(\vec{u}^{\prime} \bullet \nabla T\right) T^{\prime} d \Omega \quad=J_{1}+J_{2}=-\frac{\operatorname{Re}}{D_{t h}} \int_{\Omega}\left(u^{\prime} \frac{\partial T}{\partial r}\right) T^{\prime} d \Omega-\frac{\operatorname{Re}}{D_{t h}} \int_{\Omega}\left(w^{\prime} \frac{\partial T}{\partial z}\right) T^{\prime} d \Omega \quad$ the interactive terms between the basic state temperature and the velocity and temperature disturbances.

\section{RESULTS AND DISCUSSIONS}

\subsection{Constant ambient air temperature distribution $\left(T_{a m b}=T_{\text {cold }}\right)$}

A liquid bridge model (see Fig. 1) formed by 1 cst silicone oil $(\operatorname{Pr}=16)$ with $\Gamma=1.8(\mathrm{~L}=4.5 \mathrm{~mm}$ and $\mathrm{R}=2.5 \mathrm{~mm})$ is adopted in this subsection. With the unitary volume ratio, $V / V_{0}=1.0$, the free surface is deformed under normal gravity with the maximum of $\mathrm{h}(\mathrm{z})=1.1713$ and the minimum of $\mathrm{h}(\mathrm{z})=0.8066$. The ambient air temperature is assumed to equal the temperature of the cold rod. Therefore, the interfacial heat transfer is always heat loss from the melt to the ambient air. Figure 2 shows the dependency of $\operatorname{Re}_{c}$ upon $B i$ according to the computed results listed in Table 3, and the corresponding neutral modes are all oscillatory convections with the wave number $(m=1)$. The $\operatorname{Re}_{c}$ profile in the case of under normal gravity condition $\left(g=g_{0}\right.$, Bo $\left.=2.965\right)$ exhibits a convex dependency upon the increasing heat loss. In 
the parameter range studied, the $\operatorname{Re}_{c}$ decreases with the increasing $B i$ up to $B i \approx 1$, and this is followed by an approximately linear increase. Noted that the interfacial heat loss starts to stabilize the convection at $B i \approx 2.5$ compared to the corresponding adiabatic case. The isotherms and streamlines of the two-dimensional axisymmetric convection at the selected $\mathrm{Re}_{c}$ are shown in Fig. 3a-3c respectively. The thermal boundary layer is developed in the neighbor region of the hot end while the isotherms in the cold corner is compressed due to the concentrated streamlines induced by the shift of vortex core to the convex part of the free surface. Note that all disturbances must satisfy the no-slip boundary conditions at the solid ends, the magnitude of the disturbances inside the boundary layers should be smaller than those outside the boundary layer, and the part of the liquid bridge with largest disturbances is the most unstable. Therefore, the stability property of the basic flow is mainly determined by the "effective" temperature gradient on the middle part of the liquid bridge [15]. From this point of view, it is useful to investigate the temperature gradient at the middle part of the free surface. It is known that the interfacial heat transfer modifies the free-surface temperature distribution directly and then the thermal and flow fields. In the neighbor region of the melt free surface, the increasing interfacial heat loss pulls up the isotherms near the cold end, and the temperature gradient near the cold rod is smoothed while the temperature gradient near the hot rod is enhanced. Moreover, the vortex of the flow distributes more homogeneously in the bulk region of the liquid bridge. The net effect of the above modifications is that the temperature gradient along most part of the melt free surface gets steeper with increasing $B i$ (see Fig. 4a). 
Therefore, a lower $\operatorname{Re}_{c}$ may be required to destabilize the stationary convection with increasing interfacial heat loss. On the other hand, according to the perturbation equation of the melt free-surface heat transfer:

$$
\vec{n} \bullet \nabla T^{\prime}=-B i \times T^{\prime} \text { on } \mathrm{r}=\mathrm{h}(\mathrm{z}),
$$

whenever a positive temperature disturbance appears somewhere on the melt free surface, it is accompanied by an increase of heat loss through that part of the melt free surface, and vice versa. Therefore, the interfacial heat transfer restrains the melt free-surface temperature disturbances, especially at larger $B i$. To verify the remarks, Figure 2 also shows the numerical results that $B i$ in the perturbation equation (12) is set to be zero. With the same basic flow, the interfacial heat transfer significantly delays the onset of the oscillatory convection, and the stabilization effect gets stronger with increasing $B i$. In practice, the convex tendency of the $\mathrm{Re}_{c}$ profile shown in Fig. 2 could be due to the competition of the aforementioned two mechanisms.

For a further investigation of the physics of the instabilities, the kinetic and "thermal" energy balances normalized by the mechanical and thermal dissipation $D_{k}$ and $D_{t h}$ respectively are shown in Fig. 5a. For the "thermal" energy of the disturbance flow, the destabilizing effect (J1) is produced by the amplification of the high radial gradient of the basic thermal field mainly occurred in the bulk through the radial flow disturbances. On the other hand, in addition to the major stabilizing effect contributed by the thermal diffusion $\left(D_{t h}\right)$, the stabilizing effects are produced by the amplification of the high axial gradient of the basic thermal field (J2) mainly occurred near the hot end and cold corner through the axial flow disturbances [14] and the 
transport of "thermal" energy through the free surface (Q), the only term directly involving the effect of interfacial heat transfer. The kinetic energy is insignificant for fluids of high Pr number [14]. However, it's interesting to note that the effect of buoyant force (B) always serves the destabilization although the liquid bridge is heated from above. The rate of change of "thermal" energy with the increasing interfacial heat loss at $\mathrm{Re}=428$, the critical Reynolds number for the corresponding adiabatic case, is shown in Fig. 5b. It can be seen that the destabilizing effect (J1) overwhelms the major stabilizing effect of heat diffusion $\left(D_{\text {th }}\right)$ at small $B i$, and it is overwhelmed by the heat diffusion at large $B i$. The general trend of the corresponding $\mathrm{Re}_{c}$ profile is determined by the relative magnitude of $(\mathrm{J} 1)$ to the thermal diffusion $\left(\mathrm{D}_{\text {th }}\right)$. However, the details of the trend, such as the position of the local minimum, are also contributed by (J2) at small $B i$ while by (Q) at large $B i$.

To evaluate the effect of melt free-surface deformation on the stability of the stationary convection, an artificial case of under normal gravity condition but neglecting the melt free-surface deformation $\left(g=g_{0}, \mathrm{Bo}=0\right)$ is studied. The numerical results show that the corresponding flow fields are quite different from those in the cases with deformed domain (see Fig. 3) where the vortex cores shift to the hot corner with the crowded streamlines. Noted that the temperature gradient at the middle part of the melt free surface is flattened by the convection with the boundary layers formed at both the cold and hot ends where the temperature gradient increases sharply (see Fig. 4b). The corresponding $\operatorname{Re}_{c}$ profile roughly exhibits a similar tendency as the case of under normal gravity, however, with much lower 
quantity (see Fig. 2). It reveals the significant stabilization effect on the stationary convection through the modifications of the thermal and flow fields due to the free-surface deformation. The corresponding neutral mode keeps $(\mathrm{m}=1)$. On the other hand, the $\operatorname{Re}_{c}$ profile exhibits a local maximum roughly at $B i=1$. Note that the temperature gradient distribution along the free surface exhibits the similar configuration in the middle part of the free surface except that it exhibits undulation at the lower half of the free surface in the range of small $B i$ (see Fig. 4b). The configuration transition of the temperature gradient distributions at $B i=1$ coincidently corresponds to appearance of the local maximum of the $\operatorname{Re}_{c}$ profile. The details of the relationship between the undulation of temperature gradient distribution and the sudden increasing stabilizing effect of the flow need further investigation. Figure 6 shows the corresponding results of the energy analysis. Similar to the case with the free surface deformation, the destabilizing effect for the "thermal" energy of the disturbances flow is produced by the radial energy transfer from the basic thermal field to the disturbance flow (J1). The main stabilizing effects are contributed by the thermal diffusion $\left(\mathrm{D}_{\mathrm{th}}\right)$ and the axial energy transfer from the basic thermal field to the disturbance flow (J2). The rate of change of "thermal" energy as a function of $B i$ at $\operatorname{Re}=292$, the critical Reynolds number for the corresponding adiabatic case, is shown in Fig. 6b. It can be seen that the destabilizing effect (J1) generally exhibits a convex trend while it keeps nearly constant in the range of $B i$ from 0.5 to 1.0 . The stabilizing effect $(\mathrm{J} 2)$ also exhibits a concave trend with a local minimum at $B i=1.0$. The coupling of the above contra-effects and the thermal 
diffusion $\left(\mathrm{D}_{\mathrm{th}}\right)$ results in local maximum suppressing of the instability at $B i=1$ in the rate of the "thermal" energy $\left(\mathrm{E}_{\mathrm{th}}\right)$ change of the disturbance, which corresponds to the appearance of the local maximum of the $\operatorname{Re}_{c}$ profile at $B i=1$.

\subsection{Linear ambient air temperature distribution $\left(T_{a m b}=z / \Gamma-0.5\right)$}

In this subsection, the same liquid bridge model as that in the subsection 3.1 is adopted except that the ambient air temperature is assumed to be linearly distributed along the axial direction $[4,5]$. Therefore, it is heat-loss to the ambient air at the lower part of the free surface while heat-gain from the ambient air at the upper part of the free surface (see Fig. 7a). With the increasing interfacial heat transfer, the isotherms and streamlines of the two-dimensional axisymmetric convection (not shown) at the corresponding $\operatorname{Re}_{c}$ behave quite similarly to the case with $\left(T_{a m b}=T_{\text {cold }}\right)$ (see Fig. 3), so does the temperature gradient distribution on the middle part of the free surface (see Fig. 7b), which gets steeper with the increasing Bi. On the other hand, the temperature gradient at the lower part of the free surface in the present case is increased compared with Fig. $4 \mathrm{a}$ at the same $B i$, the distributions of the "effective" temperature gradient, therefore, behave more smoothly. Figure 8 shows the dependency of $\operatorname{Re}_{c}$ upon $B i$ according to the computed results listed in Table 4. Due to the two coupling mechanisms mentioned in the subsection 3.1 (Figure 8 also shows the numerical results that $B i$ in the perturbation equation (12) is set to be zero), the $\mathrm{Re}_{c}$ profile roughly exhibits a similar convex tendency as the corresponding case with $\left(T_{\text {amb }}=T_{\text {cold }}\right)$ except the appearance of local maximum $\operatorname{Re}_{c}$ in the range of 
small $B i$. In the parameter range studied, the wave number of the corresponding neutral mode is also $(\mathrm{m}=1)$. The kinetic and "thermal" energy balances normalized by the mechanical and thermal dissipation $D_{k}$ and $D_{t h}$ respectively are shown in Fig. 9a. In the "thermal" energy of the disturbances flow, the energy transfer from the basic thermal field through the radial flow disturbances (J1) always serves as the destabilizing effect. Both the thermal diffusion $\left(D_{t h}\right)$ and the effect involving the direct effect of interfacial heat transfer (Q) serve as the stabilizing effect, while the latter is much less important in the energy contribution. The energy transfer from the basic thermal field through the axial flow disturbances (J2) also behaves as the stabilizing effect until it reverses to serve as the destabilizing effect at large $B i$. The rate of change of "thermal" energy with the increasing interfacial heat transfer at $R e=$ 356, the critical Reynolds number for the case $(B i=1)$, is shown in Fig. 9b. It can be seen that in the range of small $B i$, the stability property of the stationary convection is determined by the contributions from the destabilizing energy transfer (J1), the stabilizing energy transfer (J2) and the thermal diffusion $\left(D_{\text {th }}\right)$. The destabilizing energy transfer (J1) overwhelms the heat diffusion (Q) and exhibits a local minimum around $B i=0.5$. On the other hand, the destabilizing energy transfer (J2) nearly keeps constant until $B i=0.5$. The net effect of the coupling stabilizing energy transfer and the destabilizing energy transfer results in local maximum suppressing of the instability at $B i=0.5$ in the rate of the "thermal" energy $\left(\mathrm{E}_{\mathrm{th}}\right)$ change of the disturbance, which may relate to the appearance of the local maximum of the corresponding $\operatorname{Re}_{c}$ profile. Finally, the effect of melt free-surface deformation on 
the stability of the stationary convection was briefly studied as shown in Fig. 9. For the artificial case of under normal gravity condition but neglecting the melt free-surface deformation $\left(g=g_{0}, \mathrm{Bo}=0\right)$, the corresponding $\operatorname{Re}_{c}$ profile exhibits a similar convex tendency as the case of under normal gravity. Noted that the profile does not exhibit any local maximum in the parameter range studied. The computed results also reveal the significant stabilization effect on the stationary convection through the modifications of the thermal and flow fields due to the free-surface deformation.

\section{Conclusions}

In the present paper, effect of interfacial heat transfer on the onset of oscillatory convection in liquid bridges formed by 1 cst silicone oil on the ground is systematically studied in an extended range of $B i$. With both the constant and linear ambient air temperature distributions, the numerical results show that the interfacial heat transfer modifies the free surface temperature distribution directly and then induces a steeper temperature gradient on the middle part of the free surface, which may destabilize the convection. On the other hand, the interfacial heat transfer restrains the temperature disturbances on the free surface, which may stabilize the convection. The two coupling effects result in a complex dependence of the stability property on the Biot number, and the appearance of the local maximum of the $\operatorname{Re}_{c}$

profile closely relates to the ambient temperature distribution. Moreover, the computed results reveal that the effect of free-surface deformation serves a significant 
stabilization on the two-dimensional axisymmetric stationary convection. To better understand the mechanism of the instabilities, rates of kinetic energy change and "thermal" energy change of the critical disturbances were also investigated. The "thermal" energy of the disturbances, which is important in liquid bridges of large Prandtl number, is mainly produced by the interaction between the basic thermal field and the flow disturbances and the thermal diffusion $\left(D_{\text {th }}\right)$. The net work of the coupling effects above determines the stability property of the oscillatory convection in the liquid bridge. 


\section{References}

[1] D, Schwabe, in: H. C. Freyhardt (ED.), Crystals 11, 75-122, Springer, Berlin, 1988.

[2] M. Levenstam, G. Amberg, and C. Winkler, Instability of thermocapillary convection in a half-zone at intermediate Prandtl numbers, Phys. Fluids 13 (2001) 807-816.

[3] Y. Kamotani, L. Wang, S. Hatta, A. Wang, and S. Yoda, Free surface heat loss effect on oscillatory thermocapillary flow in liquid bridges of high Prandtl number fluids, Int. J. Heat and Mass Transfer 46 (2003) 3211-3220.

[4] M. Irikura, Y. Arakawa, I. Ueno, and H. Kawamura, Effect of ambient fluid flow upon onset of oscillatory thermocapillary convection in half-zone liquid bridge, Microgravity Sci. Technol. XVI-I (2005) 176-180.

[5] Y. Kousaka, and H. Kawamura, Numerical study on the effect of heat loss upon the critical Marangoni number in a half-zone liquid bridge, Microgravity Sci. Technol. XVIII-3(4) (2006) 141-145.

[6] A. Mialdum and V. Shevtsova, Microgravity Sci. Technol. XVI, (2006) 146-149.

[7] D.E. Melnikov and V.M. Shevtsova, Thermocapillary convection in a liquid bridge subjected to interfacial cooling, Microgravity Sci. Technol. XVIII-3(4) (2006) $128-131$.

[8] A. Wang, Y. Kamotani, S. Yoda, Oscillatory thermocapillary flow in liquid bridges of high Prandtl number fluid with free surface heat gain, Int. J. Heat and Mass Transfer 50 (2007) 4195-4205 
[9] V. Shevtsova, Thermal convection in liquid bridges with curved free surfaces: Benchmark of numerical solutions, J. Crystal Growth 280, (2005) 632-651

[10] G. Chen, A. Lizée, and B. Roux, Bifurcation analysis of thermocapillary convection in cylindrical liquid bridges, J. Crystal Growth 180 (1997) 638-647.

[11] H.C. Kuhlmann and H.J. Rath, Hydrodynamic instabilities in cylindrical thermocapillary liquid bridges, J. Fluid Mech. 247 (1993) 247-274.

[12] G.P. Neitzel, K.T. Chang, D. F. Jankowski and H.D. Mittelmann, Linear stability theory of thermocapillary convection in a model of the float-zone crystal-growth process, Phys. Fluids A5 (1993) 108-114.

[13] G.H. Golub, and C.F. Van Loan, Matrix Computations, Johns Hopkins University Press, Baltimore, 1996.

[14] CH. Nienh üser, H. C. Kuhlmann, Stability of thermocapillary flows in non-cylindrical liquid bridges, J. Fluid Mech. 458,(2002) 35-73.

[15] D. Schwabe, Hydrothermal waves in a liquid bridge with aspect ratio near the Rayleigh limit under microgravity. Phys. Fluids 17, (2005) 112104. 
Table 1: Thermophysical properties of 1cst silicone oil

\begin{tabular}{|c|c|c|c|}
\hline$\rho_{0}$ & $818\left(\mathrm{~kg} / \mathrm{m}^{3}\right)$ & $\beta$ & $0.00129\left(\mathrm{~K}^{-1}\right)$ \\
\hline$v$ & $10^{-6}\left(\mathrm{~m}^{2} / \mathrm{s}\right)$ & $\gamma$ & $5.63 \times 10^{-5}\left(\mathrm{~kg} / \mathrm{s}^{2}\right)$ \\
\hline $\mathrm{K}$ & $2.4 \times 10^{-2}(\mathrm{cal} / \mathrm{m} \cdot \mathrm{s} \cdot \mathrm{k})$ & $\sigma_{0}$ & $16.9 \times 10^{-3}(\mathrm{~N} / \mathrm{m})$ \\
\hline
\end{tabular}


Table2: code validation

(a): $\operatorname{Pr}=0.02, \operatorname{Re}=2000, g=0$

\begin{tabular}{|c|c|c|c|c|}
\hline & $\begin{array}{l}\text { Aspect } \\
\text { ratio }\end{array}$ & $\begin{array}{c}\text { contact angle at } \\
\text { hot rod: } \alpha_{h}\end{array}$ & $\begin{array}{c}\text { Present code } \\
N_{r} \times N_{z}=51 \times 71\end{array}$ & Ref. [9] \\
\hline \multirow[t]{4}{*}{$|\psi|_{\max }$} & \multirow[t]{2}{*}{$\Gamma=1$} & $40^{\circ}$ & 8.62 & 8.42 \\
\hline & & $140^{\circ}$ & 25.04 & 24.67 \\
\hline & \multirow[t]{2}{*}{$\Gamma=1.2$} & $40^{\circ}$ & 5.76 & 5.61 \\
\hline & & $140^{\circ}$ & 21.76 & 21.95 \\
\hline \multirow[t]{4}{*}{$|w|_{\max }$ on free } & \multirow[t]{2}{*}{$\Gamma=1$} & $40^{\circ}$ & 190.59 & 188.61 \\
\hline & & $140^{\circ}$ & 182.05 & 182.95 \\
\hline & \multirow[t]{2}{*}{$\Gamma=1.2$} & $40^{\circ}$ & 188.39 & 184.46 \\
\hline & & $140^{\circ}$ & 190.40 & 202.55 \\
\hline
\end{tabular}

(b): $\operatorname{Pr}=4, \Gamma=1, g=0, \mathrm{Bi}=0$

\begin{tabular}{|c|c|c|c|}
\hline $\begin{array}{c}\text { contact angle at hot } \\
\text { rod: } \alpha_{h}\end{array}$ & $\mathrm{~m}$ & Present code & Ref. [14] \\
\hline $30^{\circ}$ & 1 & 1293 & 1350 \\
\hline $50^{\circ}$ & 1 & 1487 & 1470 \\
\hline $90^{\circ}$ & 2 & 1449 & 1445 \\
\hline $110^{\circ}$ & 2 & 996 & 1010 \\
\hline $130^{\circ}$ & 2 & 865 & 840 \\
\hline
\end{tabular}


Table 3: $\boldsymbol{R} \boldsymbol{e}_{c}$ versus $B \boldsymbol{i}$ when $T_{a m b}=-0.5$

\begin{tabular}{|c|c|c|}
\hline$B i$ & $\mathrm{~g}=\mathrm{g}_{0}, \mathrm{Bo}=0$ & $\mathrm{~g}=\mathrm{g}_{0}, \mathrm{Bo}=2.965$ \\
\hline 0 & 292 & 428 \\
\hline 0.3 & 270 & 386 \\
\hline 0.5 & 281 & 356 \\
\hline 1.0 & 337 & 334 \\
\hline 1.5 & 332 & 356 \\
\hline 2.0 & 325 & 395 \\
\hline 3.0 & 346 & 475 \\
\hline 4.0 & 389 & 544 \\
\hline 5.0 & 442 & 610 \\
\hline
\end{tabular}


Table 4: $\boldsymbol{R} \boldsymbol{e}_{c}$ versus $B \boldsymbol{i}$ when $T_{a m b}=z / \Gamma-0.5$

\begin{tabular}{|c|c|c|}
\hline$B i$ & $\mathrm{~g}=\mathrm{g}_{0}, \mathrm{Bo}=0$ & $\mathrm{~g}=\mathrm{g}_{0}, \mathrm{Bo}=2.965$ \\
\hline 0 & 292 & 428 \\
\hline 0.2 & 275 & 452 \\
\hline 0.5 & 257 & 465 \\
\hline 1.0 & 240 & 356 \\
\hline 1.5 & 234 & 323 \\
\hline 2.0 & 234 & 317 \\
\hline 3.0 & 247 & 336 \\
\hline 4.0 & 270 & 373 \\
\hline 5.0 & 293 & 417 \\
\hline
\end{tabular}




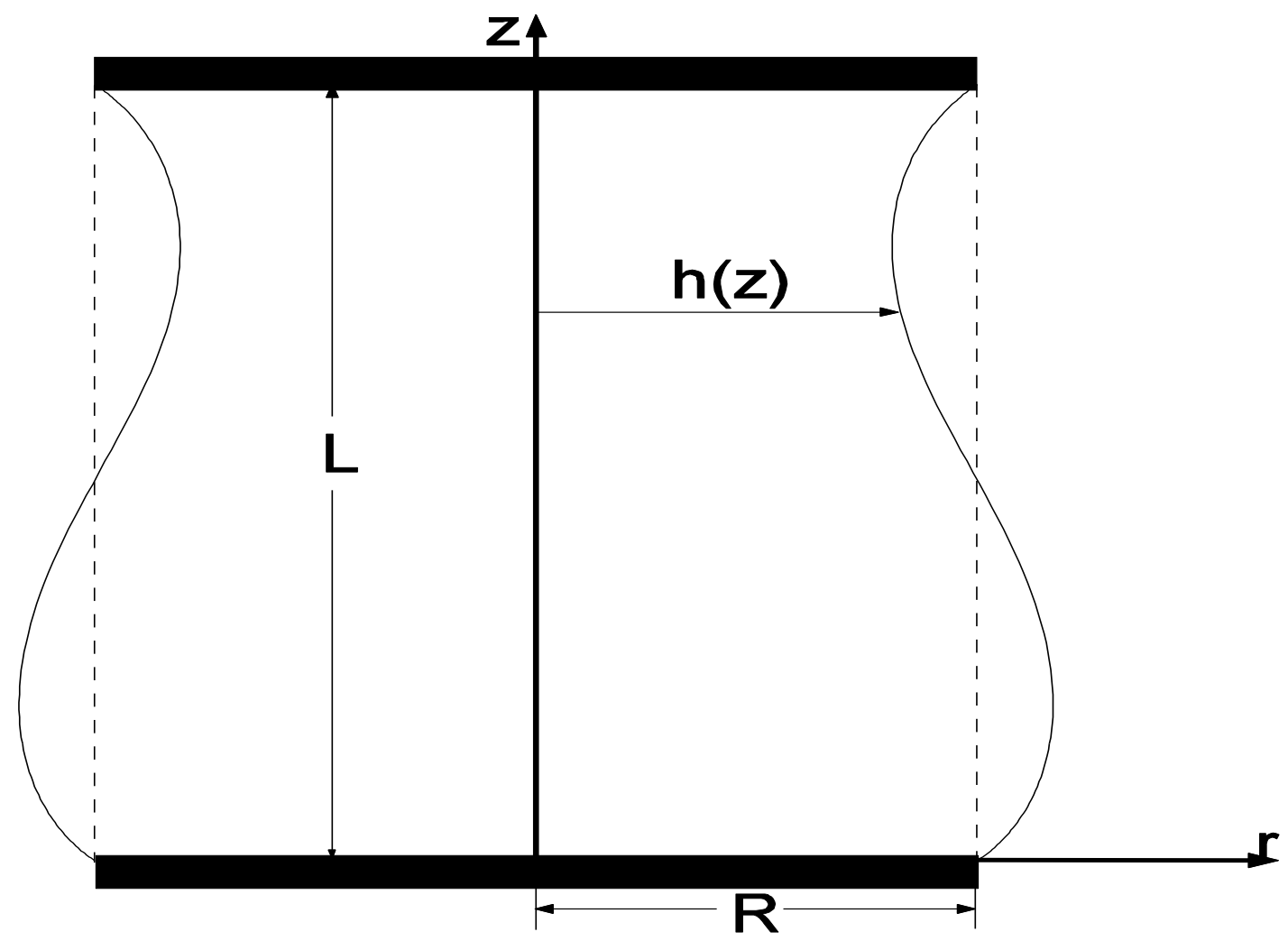

Figure 1. Scheme diagram of a liquid bridge. 


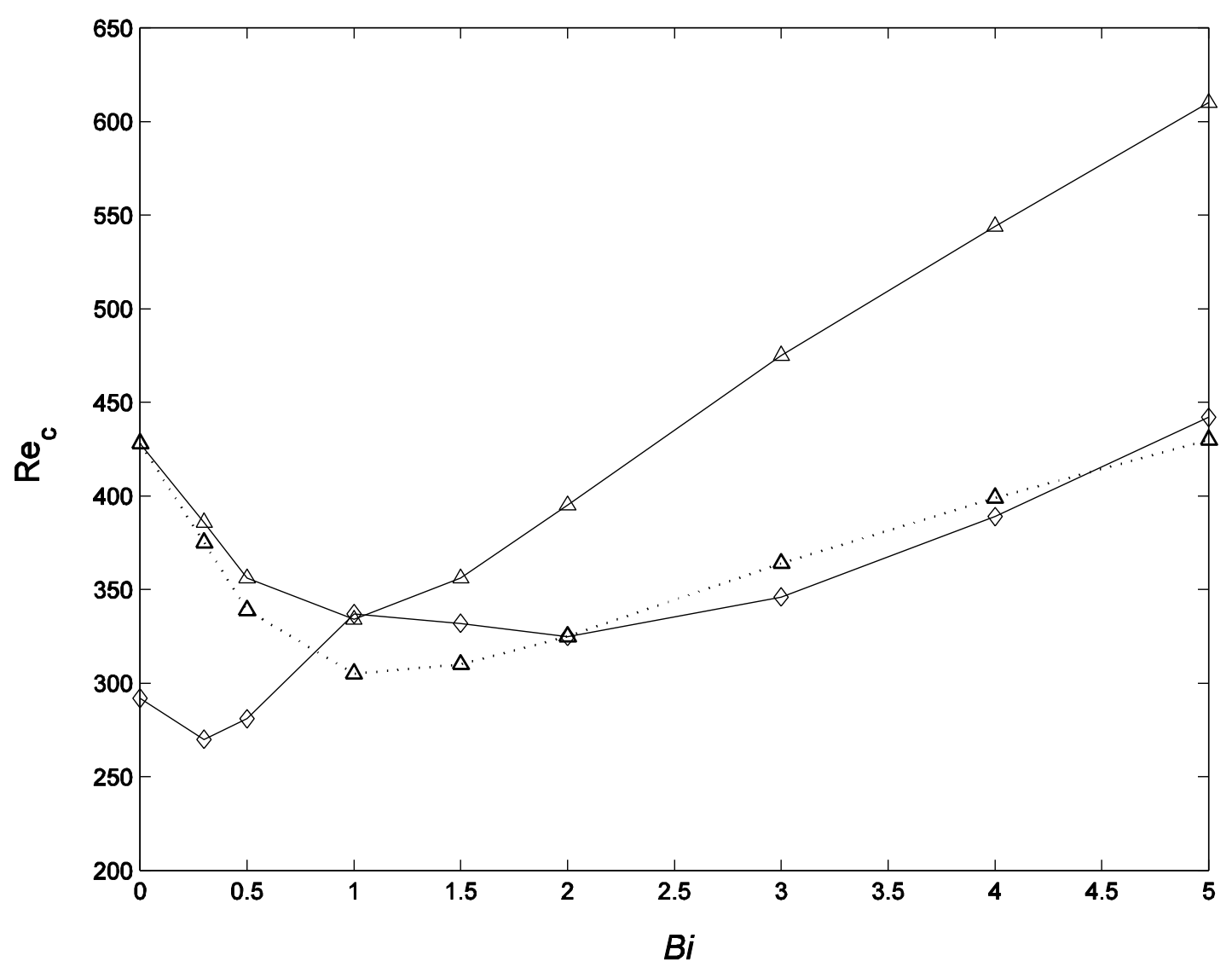

Figure 2. Critical Reynolds number versus Bi for cases of $T_{a m b}=-0.5:\left(\mathrm{g}=\mathrm{g}_{0}, \mathrm{Bo}=\right.$ 0 )-diamond points on solid line; $\left(\mathrm{g}=\mathrm{g}_{0}, \mathrm{Bo}=2.965\right)$-triangle points on solid line and $\left(\mathrm{g}=\mathrm{g}_{0}, \mathrm{Bo}=2.965\right)$ when Biot number is set to zero in the perturbation equation (12)triangle points on the dotted line respectively. 


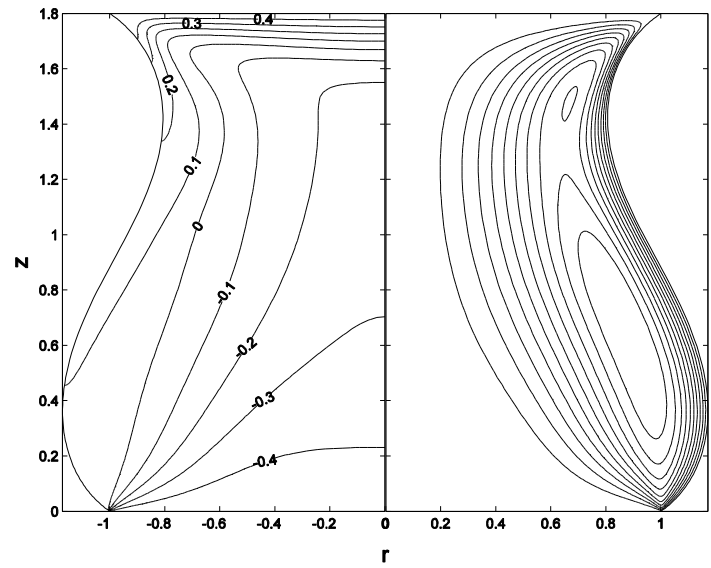

(a)

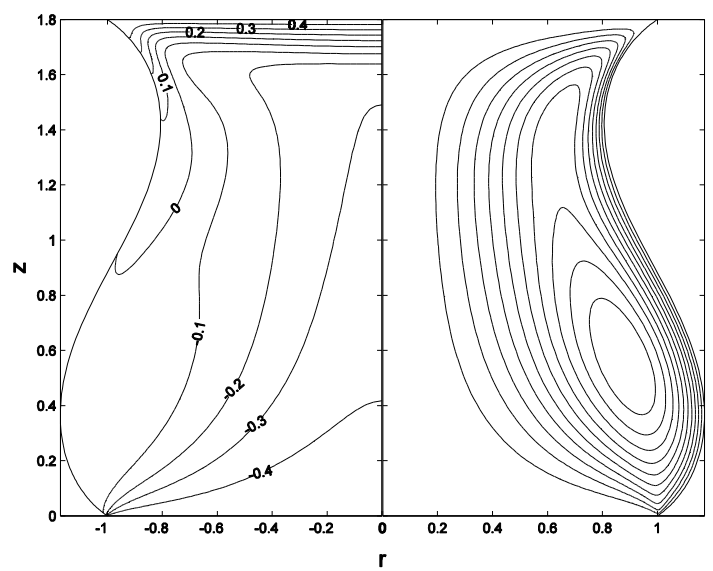

(b)

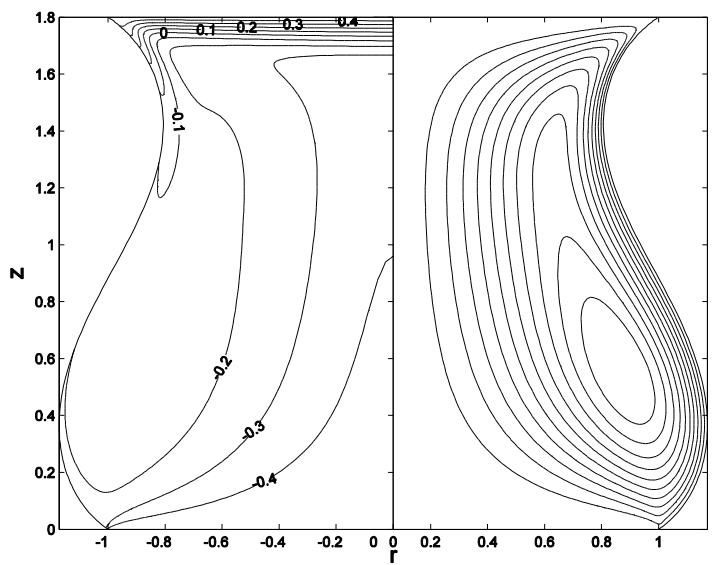

(c)

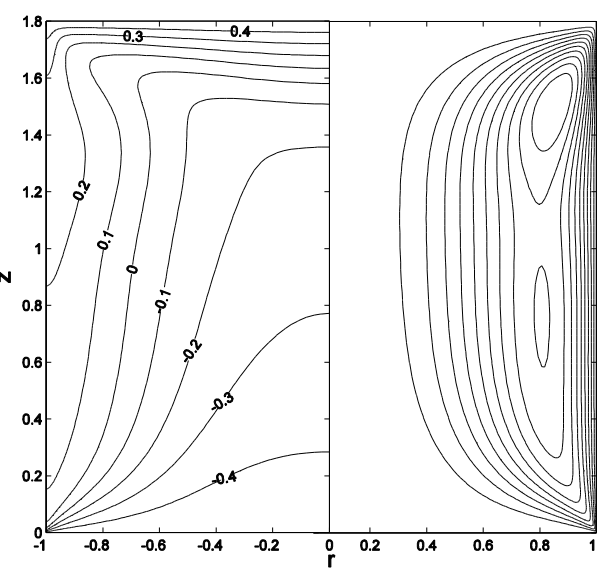

(d)

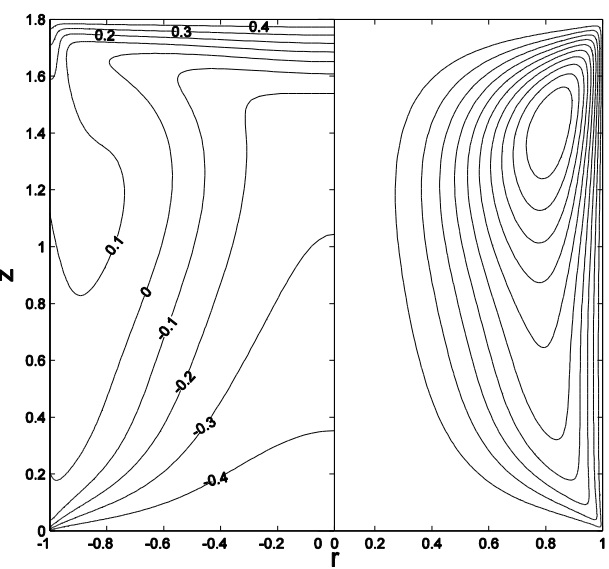

(e)

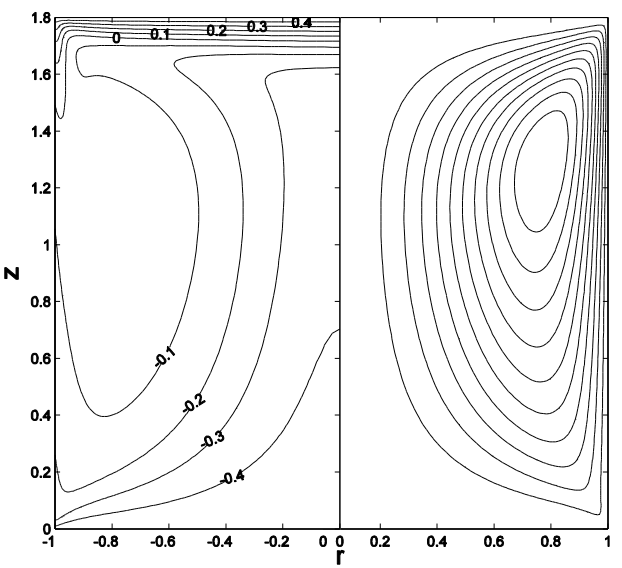

(f)

Figure 3. Isotherms and streamlines at the corresponding $\operatorname{Re}_{\mathrm{c}}$ for different $B i$ under normal gravity condition for $T_{a m b}=-0.5$ (left: $\mathrm{Bo}=2.965$, right: $\mathrm{Bo}=0$ ): (a) $B i=0$, $\mathrm{Re}_{\mathrm{c}}=428$; (b) $B i=1, \mathrm{Re}_{\mathrm{c}}=356$; (c) $B i=4, \mathrm{Re}_{\mathrm{c}}=373$; (d) $B i=0, \mathrm{Re}_{\mathrm{c}}=292$; (e) $B i=$ $1, \operatorname{Re}_{\mathrm{c}}=240 ;$ (f) $B i=4, \operatorname{Re}_{\mathrm{c}}=270$. 


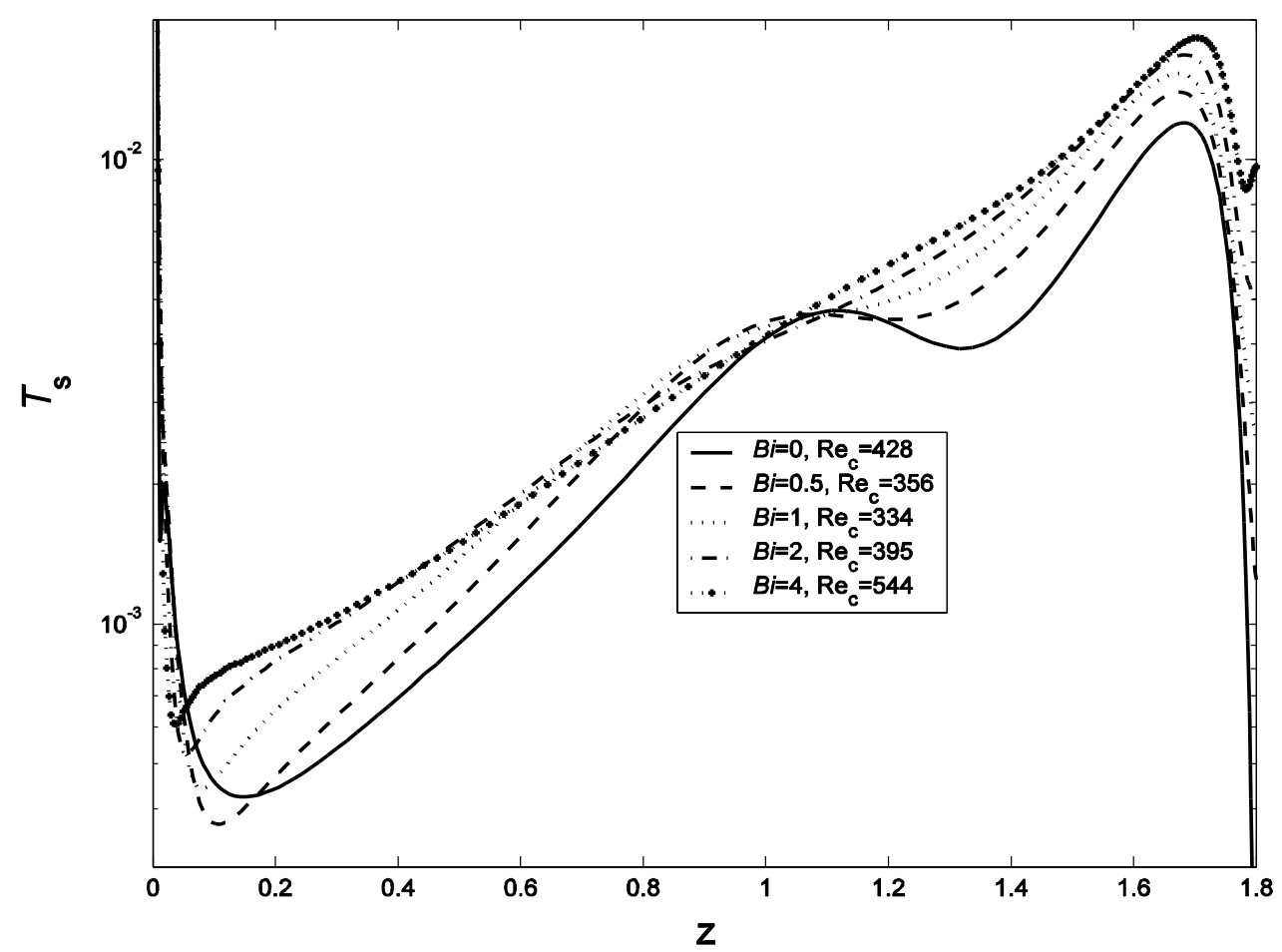

(a)

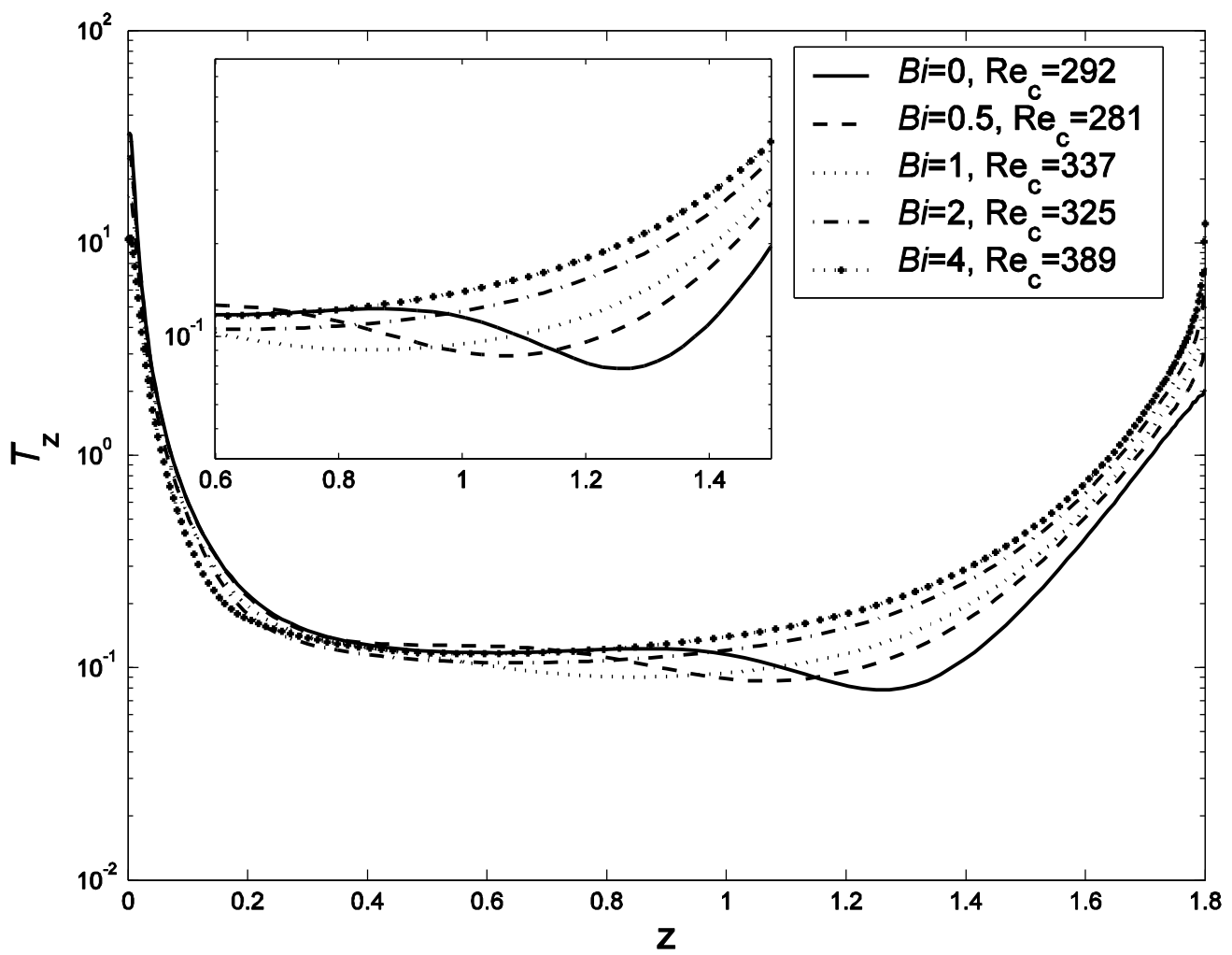

(b)

Figure 4. Temperature gradient distribution along the melt free surface at the corresponding $\operatorname{Re}_{\mathrm{c}}$ for $T_{a m b}=-0.5$ : (a) $g=g_{0}, \mathrm{Bo}=2.965$; (b) $g=g_{0}, \mathrm{Bo}=0$. 

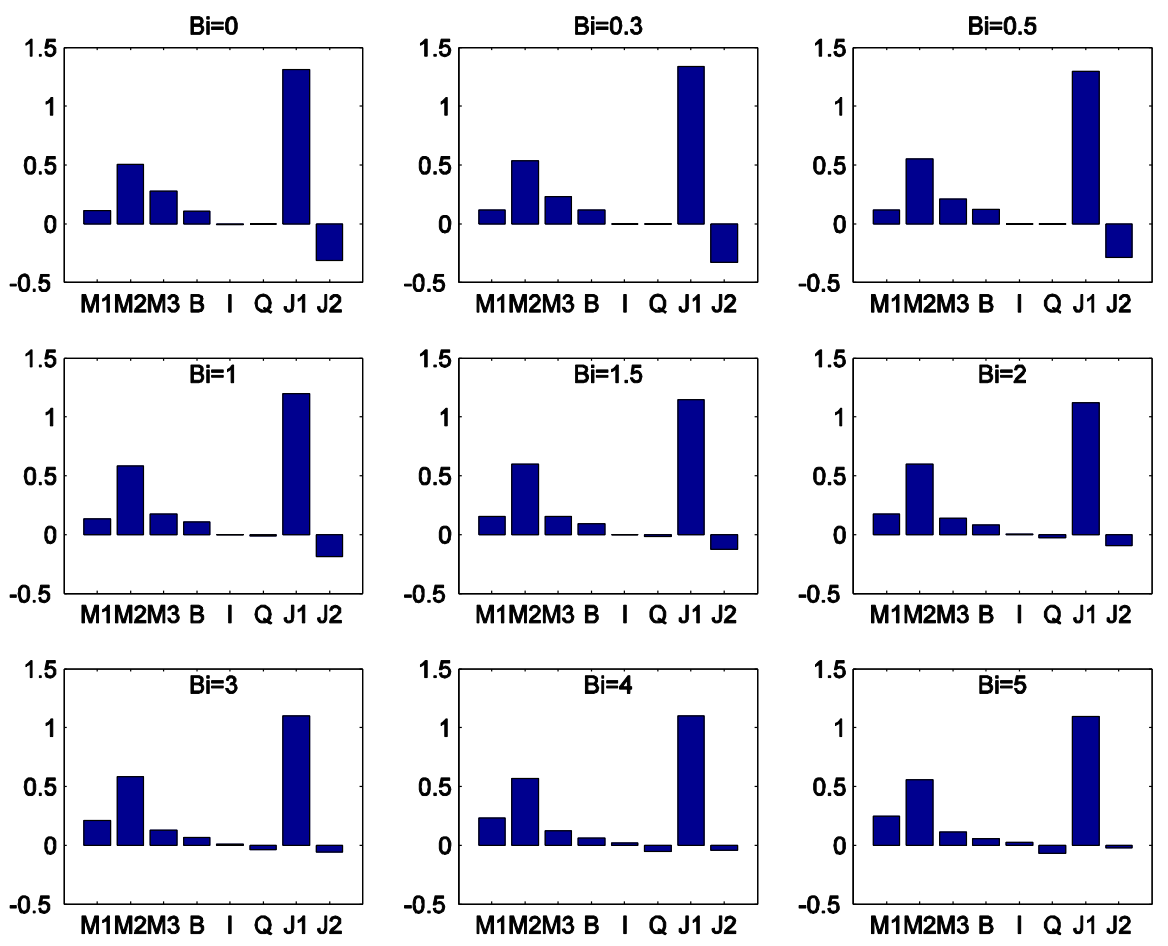

(a)

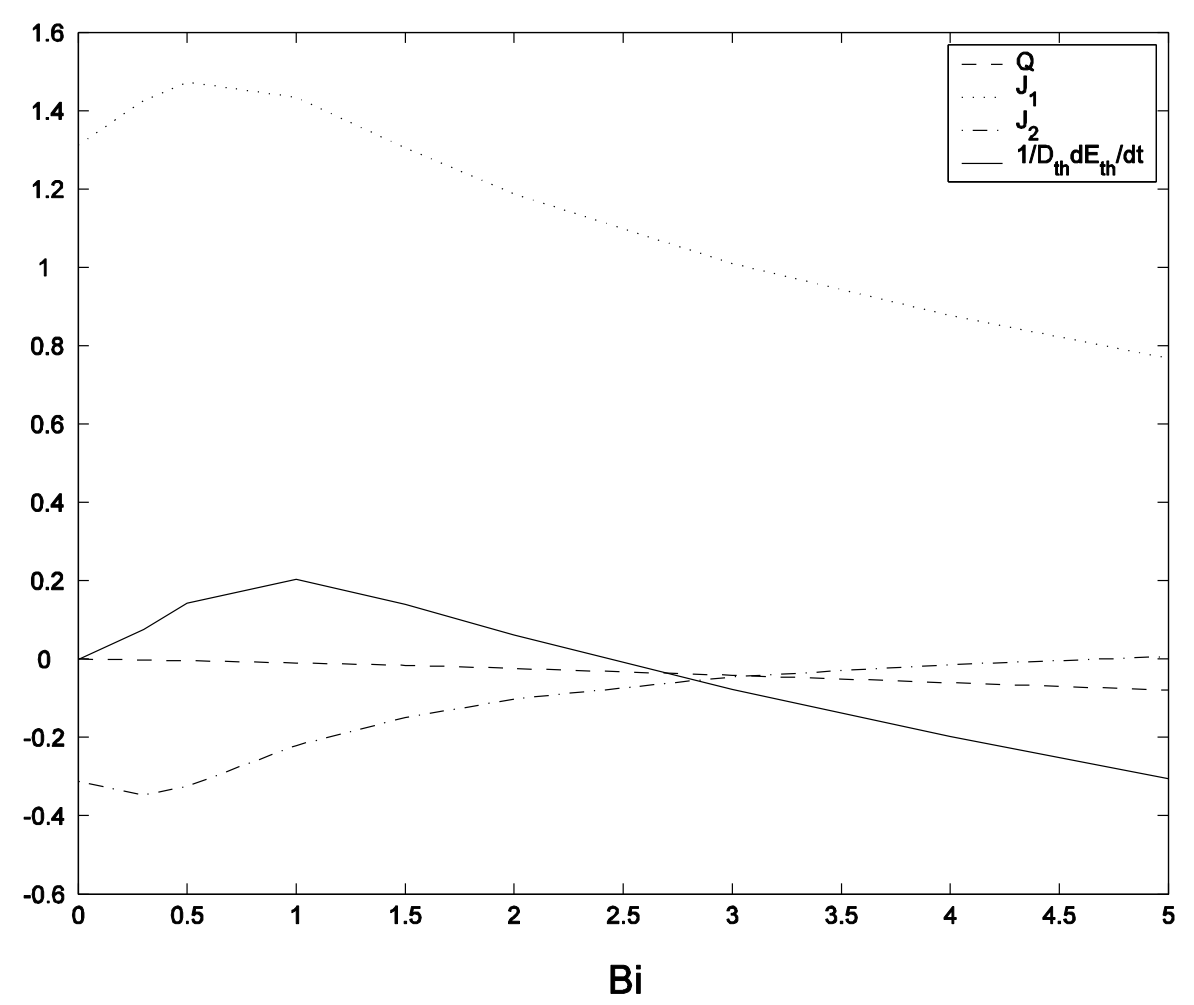

(b)

Figure 5. Kinetic and thermal Energy balance for cases of $T_{a m b}=-0.5$ when $g=g_{0}$, $\mathrm{Bo}=2.965$ at the corresponding $\operatorname{Re}_{c}$ (a) and at Re equals 428(b). 

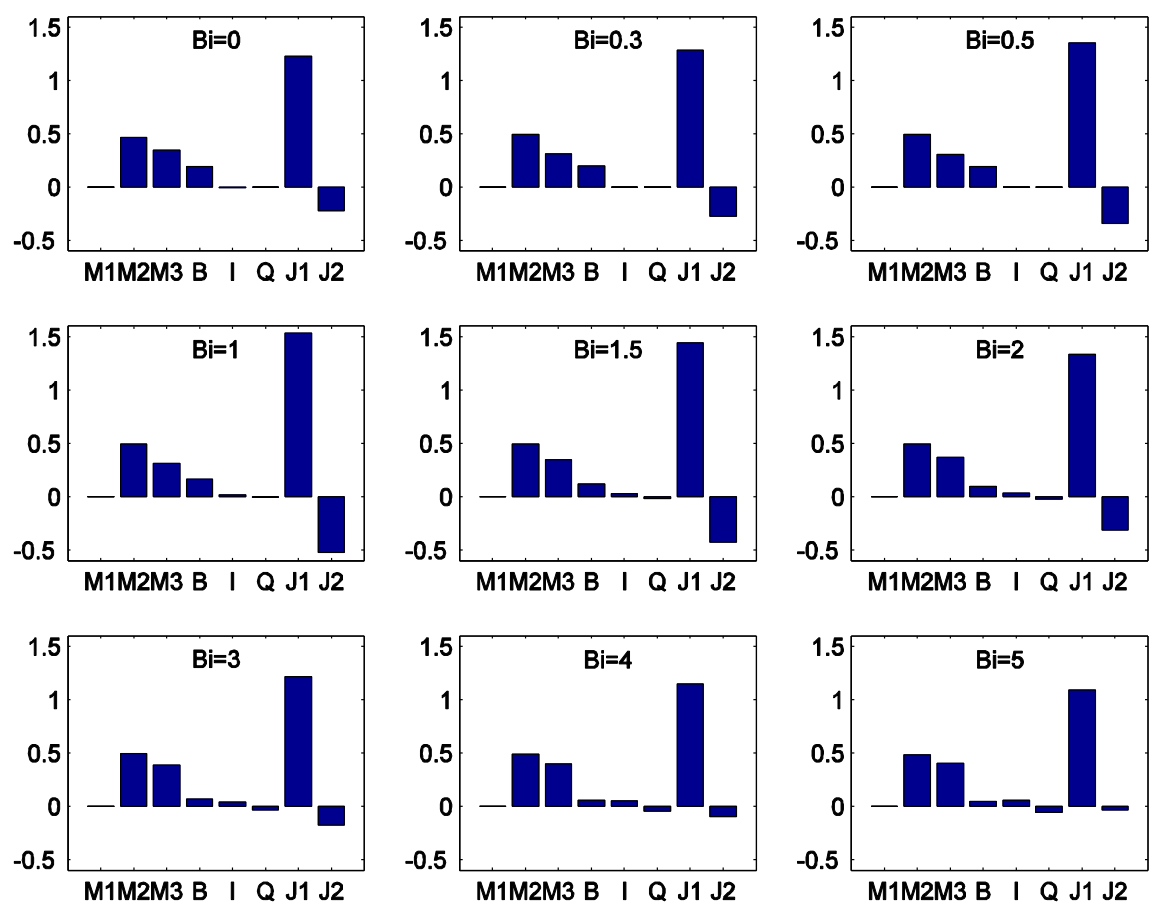

(a)

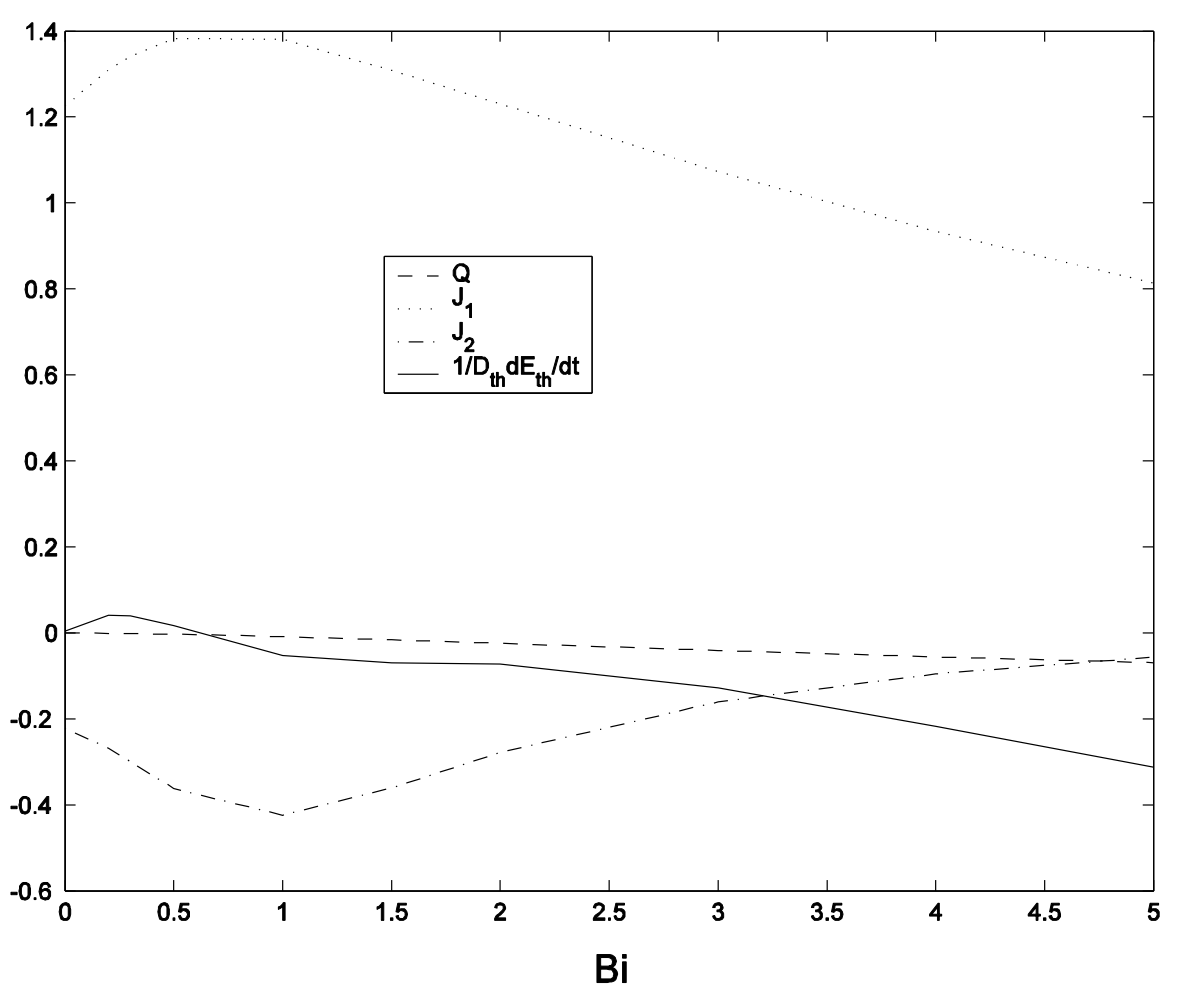

(b)

Figure 6. Kinetic and thermal Energy balance for cases of $T_{a m b}=-0.5$ when $g=g_{0}$, $\mathrm{Bo}=0$ at the corresponding $\operatorname{Re}_{c}(\mathrm{a})$ and at Re equals 292(b). 


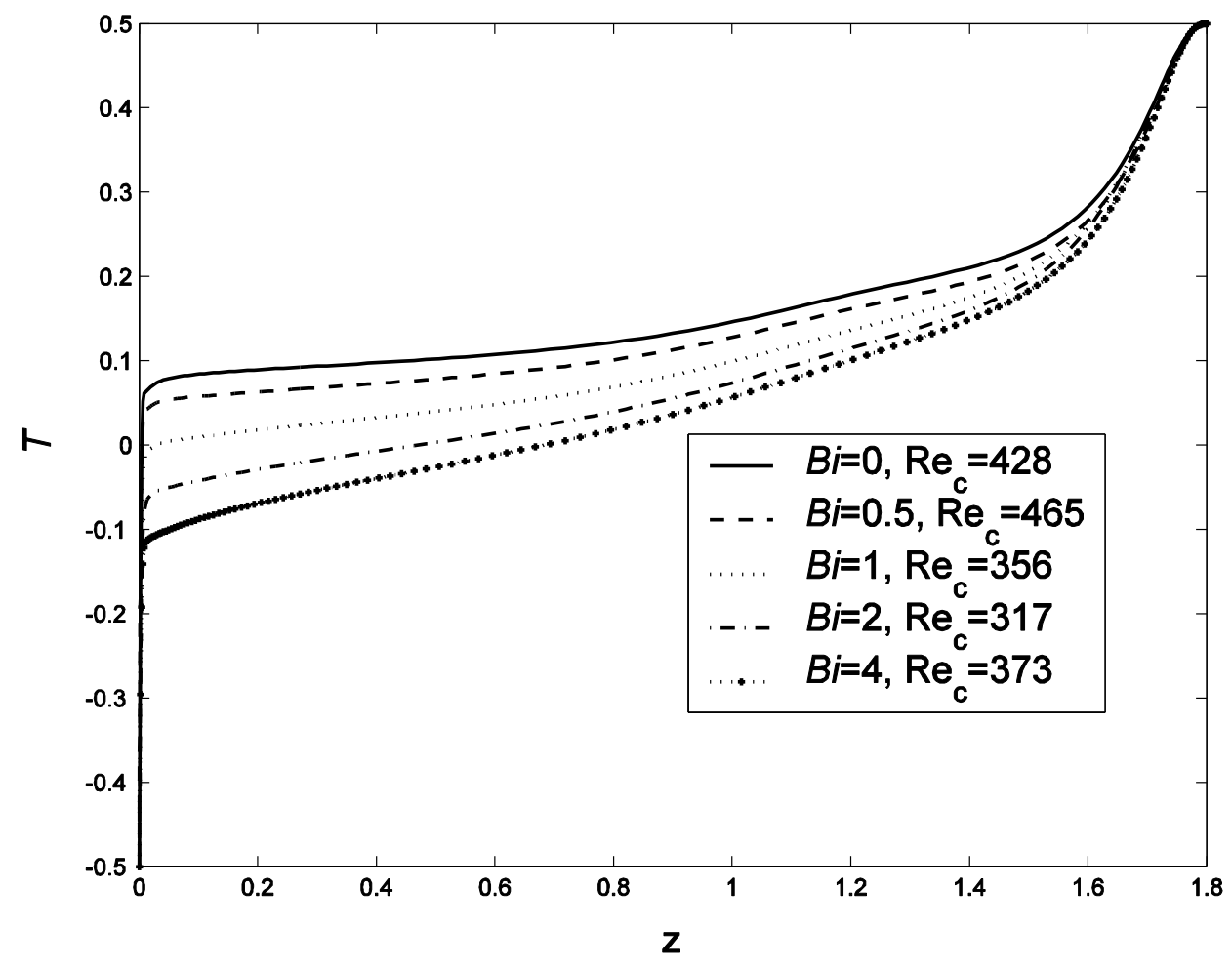

(a)

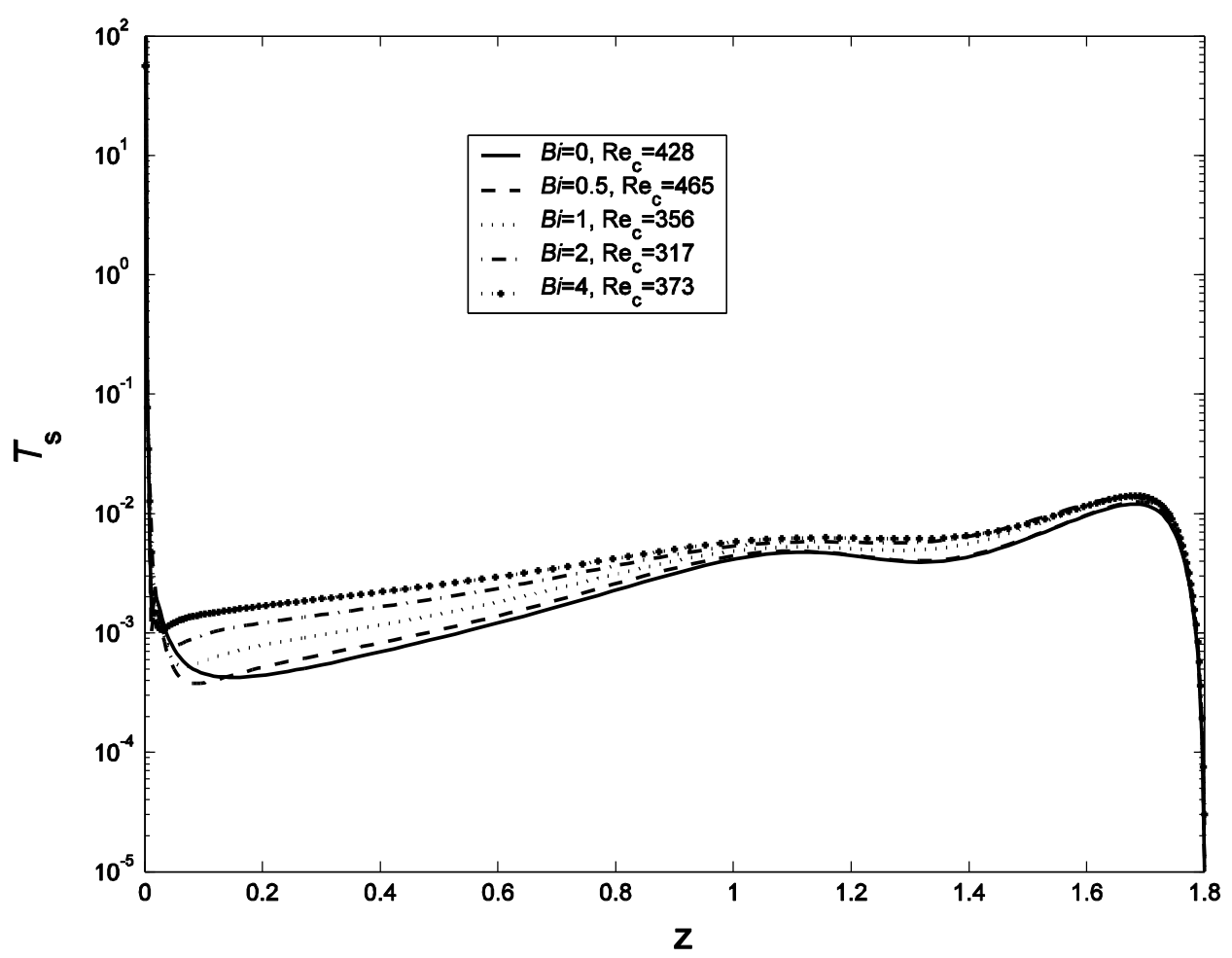

(b)

Figure 7. Temperature (a) and Temperature gradient (b) distribution on free surface at the corresponding $\mathrm{Re}_{\mathrm{c}}$ for linear $T_{a m b}$ under normal gravity condition. 


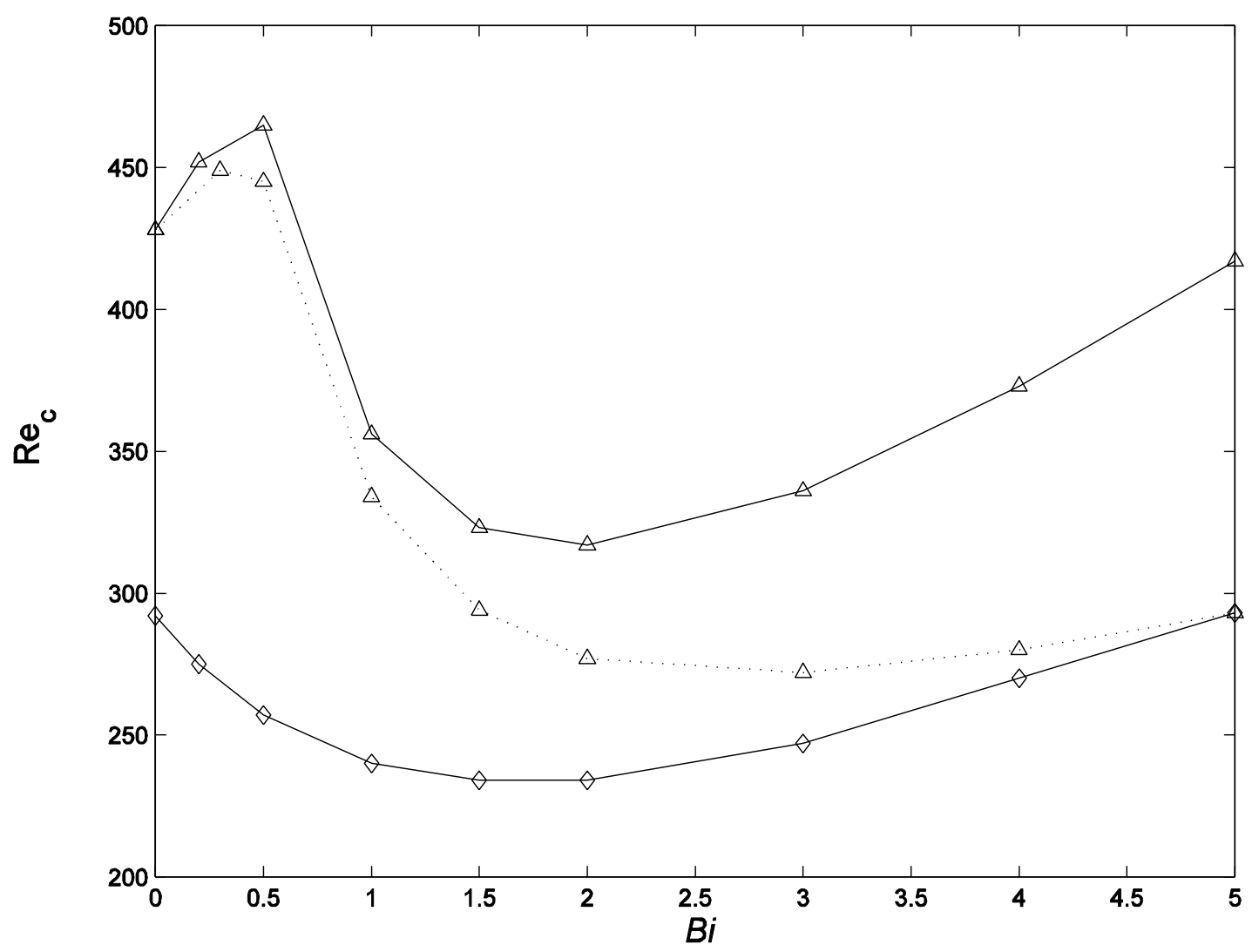

Figure 8. Critical Reynolds number versus Bi for cases of linear ambient temperature $\left(\mathrm{g}=\mathrm{g}_{0}\right.$, Bo $\left.=0\right)$-diamond points on solid line; $\left(\mathrm{g}=\mathrm{g}_{0}\right.$, Bo $\left.=2.965\right)$-triangle points on solid line and $\left(\mathrm{g}=\mathrm{g}_{0}, \mathrm{Bo}=2.965\right)$ when Biot number is set to zero in the perturbation equation (12)- triangle points on the dotted lines respectively. 

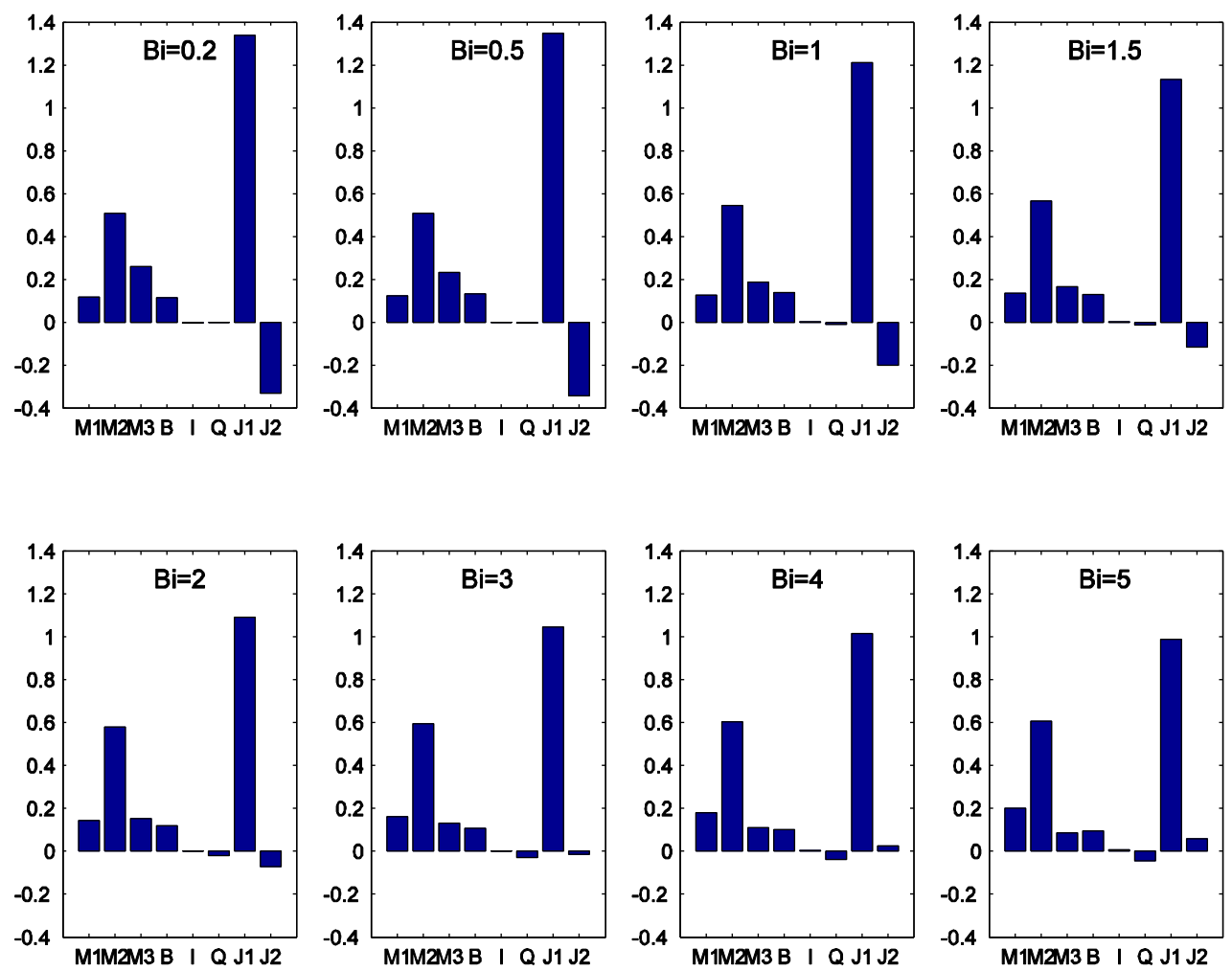

(a)

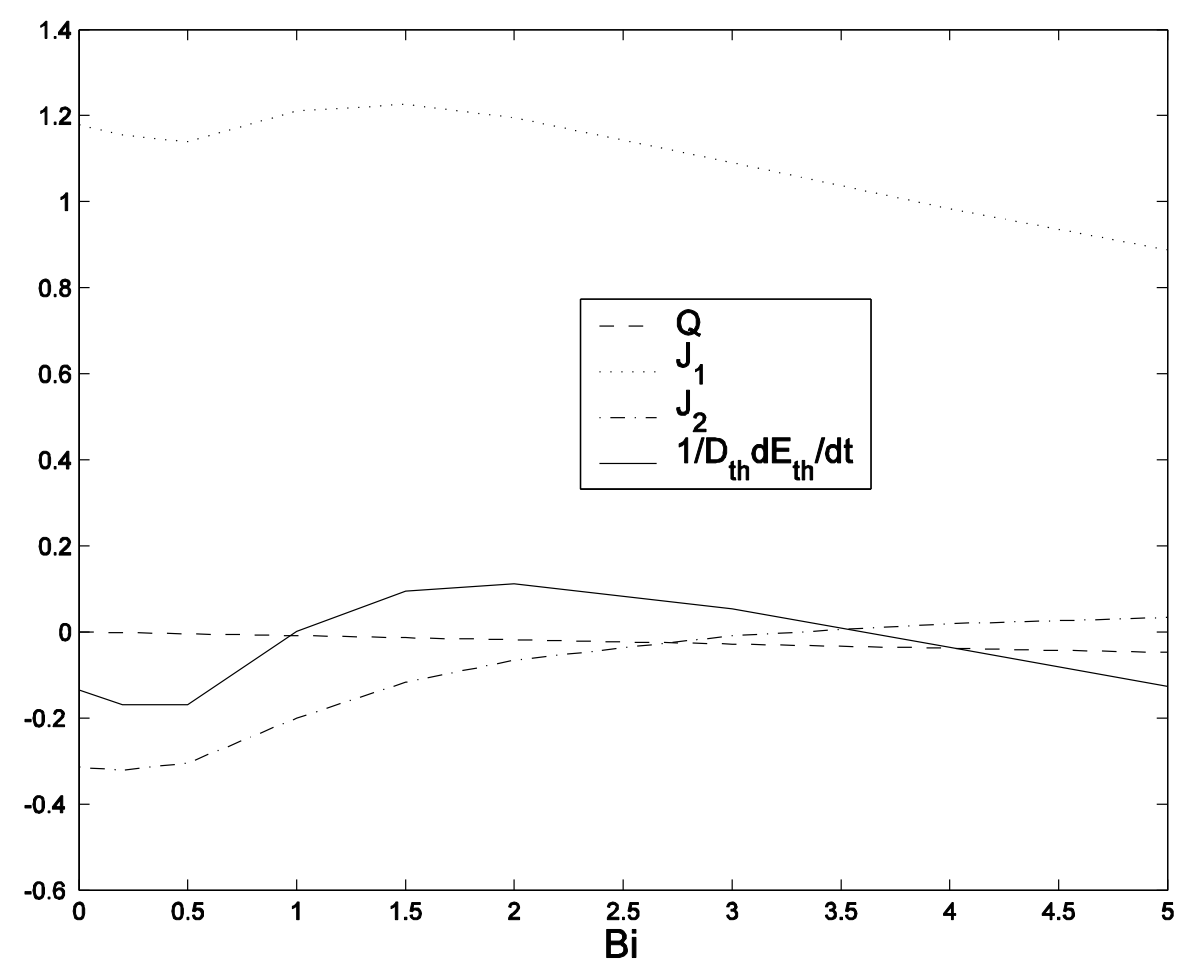

(b)

Figure 9. Kinetic and thermal Energy balance for cases of $T_{a m b}$ is linear when $g=g_{0}$, $\mathrm{Bo}=2.965$ at the corresponding $\operatorname{Re}_{c}(\mathrm{a})$ and at $\mathrm{Re}$ equals 356(b). 

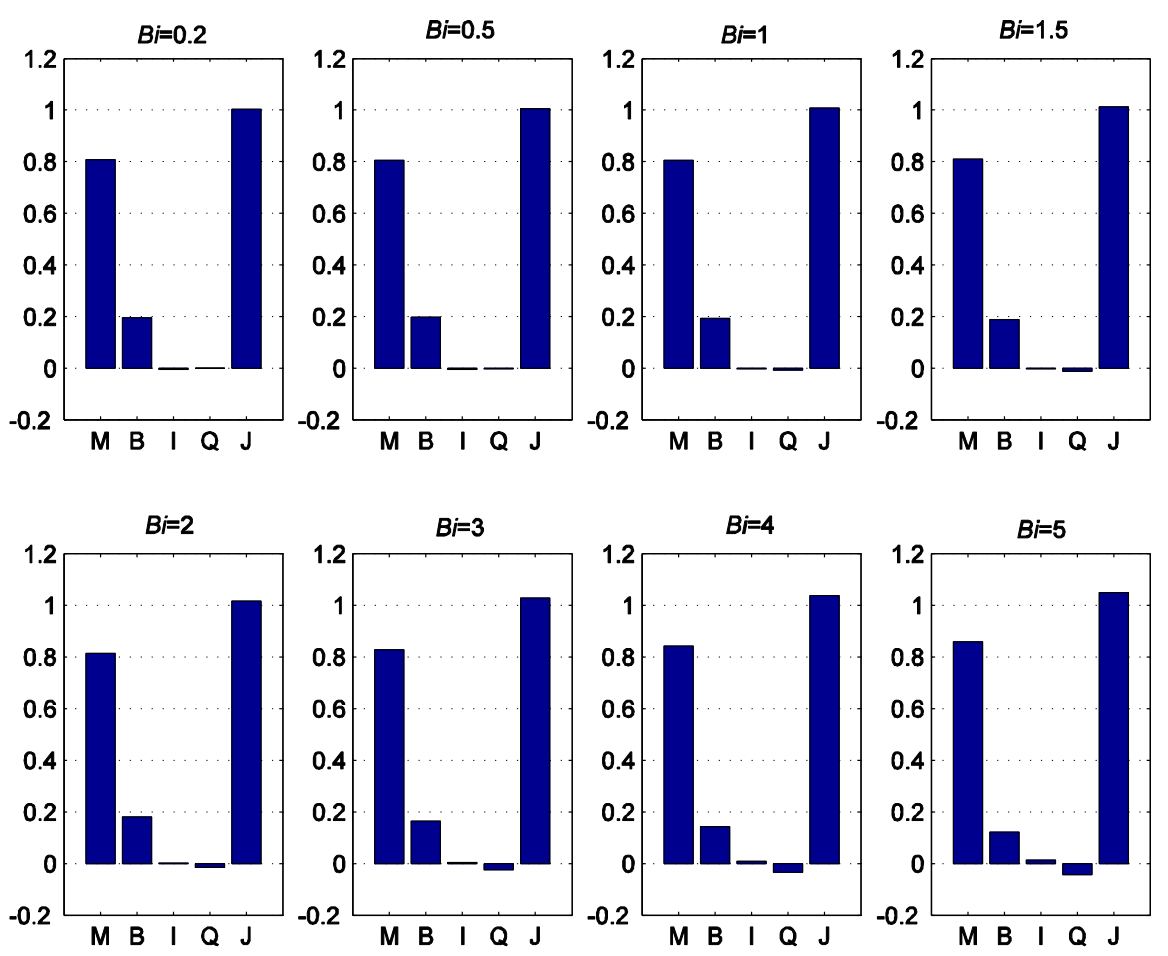

(a)

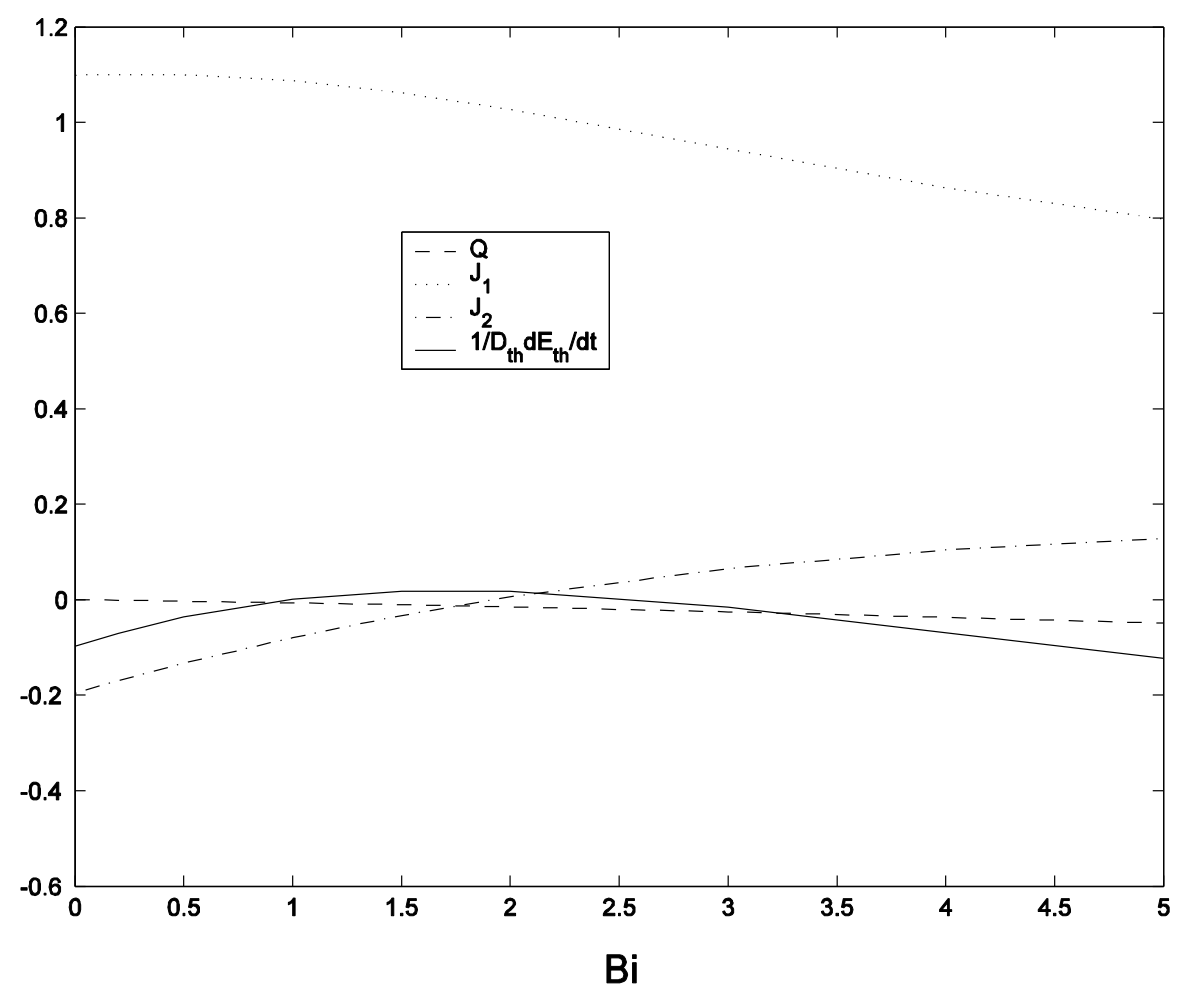

(b)

Figure 10. Kinetic and thermal Energy balance for cases of $T_{a m b}$ is linear when $g=g_{0}, \mathrm{Bo}=2.965$ at the corresponding $\operatorname{Re}_{c}(\mathrm{a})$ and at Re equals $240(\mathrm{~b})$. 